Voix et Images

voixetimages

\title{
Bibliographie de Marie-Claire Blais
}

\section{Aurélien Boivin, Lucie Robert et Ruth Major-Lapierre}

Volume 8, numéro 2, hiver 1983

Marie-Claire Blais

URI : https://id.erudit.org/iderudit/200383ar

DOI : https://doi.org/10.7202/200383ar

Aller au sommaire du numéro

Éditeur(s)

Les Presses de l’Université du Québec

ISSN

0318-9201 (imprimé)

1705-933X (numérique)

Découvrir la revue

Citer ce document

Boivin, A., Robert, L. \& Major-Lapierre, R. (1983). Bibliographie de Marie-Claire

Blais. Voix et Images, 8(2), 249-295. https://doi.org/10.7202/200383ar d'utilisation que vous pouvez consulter en ligne.

https://apropos.erudit.org/fr/usagers/politique-dutilisation/ 


\title{
BIBLIOGRAPHIE DE MARIE-CLAIRE BLAIS
}

\author{
par Aurélien Boivin, Université Laval: Lucie Robert. Université Laval \\ et Ruth Major-Lapierre. Université du Québec à Montréal.
}

Des circonstances indépendantes de notre volonté nous ont laissé quelques jours seulement pour mettre au point cette bibliographie. Nous nous excusons donc à l'avance des erreurs, imprécisions, oublis qui pourraient s'y manifester. Par la même occasion, nous voudrions remercier Roger Chamberland. Jocelyn Clavet, Réal D'Amours, André Gaulin, Kenneth Landry, Michel Lord et LouisMichel Noël du Dictionnaire des ceuvres littéraires du Québec ainsi que Dominique Chénier et Louise Myette de l'Agence Louise Myette.

\section{CEUVRES}

\section{Romans}

La Belle Bête, Québec, Institut littéraire du Québec, 1959, 214 pages.

La Belle Bête, Paris, Éditions Flammarion, 1960, 214 pages

La Belle Bête, Montréal, le Cercle du livre de France Itée, coll. CLF poche, 1968. 157 pages.

Mad Shadows, translated by Merloyd Laurence, Toronto, McClelland \& Stewart. 1960, 125 pages. (Rééditions en 1971 et 1981)

Mad Shadows, translated by Merloyd Laurence. Toronto, McClelland, coll. New Canadian Library, 1971, 125 pages.

La Hermosa Bestia, traduction espagnole de Orta Manzano, Barcelone. Ediciones Cedro, 1961, 214 pages.

La Bella Bestia, traduction italienne de B. Savarino, Milano, Bompiani, 1970.

Tête blanche. Québec, Institut littéraire du Québec, 1960, 205 pages.

Téte blanche. Montréal, les Éditions de l'Homme, 1969, 205 pages.

Tête blanche, Montréal, les Editions de l'Actuelle, 1977. 205 pages.

Tête blanche, translated by Charles Fullman, Toronto, McClelland \& Stewart Ltd., 1961, 136 pages. (Réédition en 1974)

Tête blanche, translated by Charles Fullman, Toronto, McClelland, coll. New Canadian Library, 1975, 136 pages.

Tête blanche, Boston, Little Brown, 1961, 136 pages.

Le Jour est noir, Montréal, les Éditions du Jour, coll. les romanciers du jour, 1962. 121 pages.

Le Jour est noir. Montréal, les Éditions du Jour, coll. les romanciers du jour, 1967. 124 pages. (Réédition en 1970) 
Le Jour est noir (précédé del l'Insoumise, préface d'Yves Berger, Paris, Grasset. 1971,232 pages. (La prélace d'Yves Berger a paru dans le Devoir, vol. LXII, $n^{\circ} 55$ (10 mars 1971), p. 9 \& 11 , sous le titre: $\alpha$ Une préface à l'ceuvre de Marie-Claire Blais. Une vie en accusation $x$ ).

Le Jour est noir (suivi de) l'Insoumise. Montréal, Editions internationales Stanké, coll. 10/10, 1979, 239 pages.

The Day is Dark and Three Travelers, translated by Derek Coltman, New York, Farrar, Strauss and Giroux, 1966, 182 pages. (Réédition en 1967)

Une saison dans la vie d'Emmanuel. Montréal, les Éditions du Jour, coll. les romanciers du jour, 1965, 128 pages. (Rédition en 1970)

Une saison dans la vie d'Emmanuel, Paris, Grasset éditeur, 1966, 175 pages.

Une saison dans la vie d'Emmanuel, édition de grand luxe, ornée de 35 illustrations hors-texte de Mary Meigs, montées sur papier Mayfair, composé avec le premier caractère canadien Le Cartier, relié par les Ateliers Émile Robitaille à Québec. Imprimé sur a Japon authentique " des Papeteries Rolland aux Ateliers Optima à Québec. Maquette réalisée aux Ateliers Gilles Robert. 500 exemplaires dont 25 hors commerce. Relié avec dessins en quatre couleurs, sous étui, Montréal. les Éditions du Jour, 1968, 136 pages.

Une saison dans la vie d'Emmanuel, Montréal, les Éditions du Jour, édition de semi-luxe, 1972, 136 pages.

Une saison dans la vie d'Emmanuel, Montréal, Quinze éditeur, 1976, 175 pages. (Réédition en 1978)

Une saison dans la vie d'Emmanuel. Montréal, les Éditions internationales Stanké. 1980,125 pages.

Une saison dans la vie d'Emmanuel, Montréal, les Editions internationales Stanké, coll. 10/10, 1980, 175 pages.

A Season in the Life of Emmanuel, translated by Derek Coltman, introduction by Edmund Wilson, New York, Farrar, Strauss and Giroux, 1966, 145 pages.

A Season in the Life of Emmanuel, translated by Derek Coltman, New York, Bantam Edition, coll. Pocket Book, 1975, 130 pages.

A Season in the Life of Emmanuel. translated by Derek Coltman, introduction by Edmund Wilson, Toronto, Bantam Books, coll. A Bantam Book Edition, 1976, 130 pages.

A Season in the Life of Emmanuel, translated by Derek Coltman, New York, Farrar. Strauss and Giroux, 1980,145 pages.

Une stagione nella vita di Emanuele, tradizione dal francese di Ginevra Bompiani, introduzione di Edmund Wilson, Milano. Bompiani, 1967, 160 pages.

Een winter en het leven van Emmanuel, Utrecht. A.W. Bruna, Wit beertje, no 1110. 1967, 160 pages.

Tolkikausi Emmanuelin elämästä. Suomentanut Kyllikki Villa, Porvoo. W. Söclerstrom Osakeyhtiv, 1967, 153 pages.

Una estaciön en la vida de Emmanuel, la. ed. México. Editorial Diana, 1967, 139 pages (traduit par Adolfo A. de Alba, à partir de l'édition anglaise. New York, 1966).

Et ar af Emmanuels liv, oversat af Elsebeth Juncker Ratel, Kobenhaun, S'amleren, 1967. 142 pages.

Schwarzer Winter, Kön, Kiepenheur \& Wirsch, 1967, 190 pages.

Schwarzer Winter, deutsch von Orka Brigette Fisher, Munchen, Deutscher Taschenduch Verlag. 1970, 130 pages.

Une saison dans la vie d'Emmanuel a aussi été traduit et publié en norvégien. J.-W. Cappalens Forlag, 1967; en finlandais, Werner Soderstrom O/Y, 1967; en danois, Samlerens Forlag, 1968; en hongrois, Nagylag, 1968; en polonais. Spoldzielnia Wydawnıckz, 1969: en yougoslave, Miadost Serbo-Croat, 1969 et en japonais, Shuei Sha Lid, 1974. 
L'Insoumise, Montréal, les Éditions du Jour, coll. les romanciers du jour, 1966. 119 pages. (Réédition en 1968). (Un extralt a paru dans la Presse (suppl.). vol. LXXXII, n० 78 (2 avril 1966), p. 6).

L'Insoumise (suivi de) Le Jour est noir, préface d'Yves Berger, Paris, Éditions Bernard Grasset, 1971, 232 pages. (La préface d'Yves Berger a paru dans le Devoir, vol. LXII, n 55 (10 mars 1971), p. $9 \& 11$, sous le titre: :Une préface à Iceuvre de Marle-Claire Blais. Une vie en accusation*).

L'Insoumise (précédé de) le Jour est noir. Montréal, Éditions internationales Stanké, coll. 10/10, 1979; 250 pages.

The Fugitive, translated by David Lobdell, Toronto, Oberon Press, 1978. 96 pages.

David Sterne. Montréal, les Éditions du Jour, coll. les romanciers du jour. 1967. 127 pages.

David Sterne, Montréal, les Editions internationales Stanké, coll. 10/10, 1979. 1981,137 pages.

David Sterne, translated by David Lobdell, Toronto, McClelland \& Stewart, 1972. 92 pages.

Manuscrits de Pauline Archange. Montréal, les Éditions du Jour, coll. les romanciers du jour. 1968, 127 pages.

Manuscrits de Pauline Archange, Paris, Éditions Bernard Grasset, 1968, 205 pages.

Manuscrits de Pauline Archange. Paris et Montréal, les Éditions internationales Stanké, coll. 10/10. 1981. 217 pages.

Manuscripts of Pauline Archange, translated by Derek Coltman, New York, Farrar, Strauss and Giroux, 1970, 217 pages.

Manuscripts of Pauline Archange, New York. Bantam Edition, 1976, 186 pages.

Manuscripts of Pauline Archange. Toronto, McClelland and Stewart, 1982. 186 pages.

Manuscripts of Pauline Archange and St. Lawrence Blues, préface de Marie-Claire Blais. illustrations de Mary Meigs, Toronto, House of Exile, 1977, 61 pages.

Rukopisy Pavliny Archandelske, traduction tchékosiovaque, Odeon. Prague, 1973. publié dans Pet Kanadskych.

Vivre! Vivre!, tome II des Manuscrits de Pauline Archange, Montréal, les Editions du Jour, coll. les romanciers du jour, 1969. 170 pages.

Vivre! Vivre!. Manuscrits de Pauline Archange II. Montréal et Paris, Editions internationales Stanké, coli. 10/10, 1981, 178 pages.

Part Two Manuscripts of Pauline Archange. New York, Farrar, Strauss and Giroux, 1970, 170 pages.

Part Two Manuscripts of Pauline Archange. New York, Bantam Edition, 1976. 170 pages.

Part Two Manuscripts of Pauline Archange. Toronto. McClelland and Stewart. 1982, 170 pages. (La traduction anglaise de Vivre! Vivre! a paru dans le même volume que celle des Manuscrits de Pauline Archangel.

Les Apparences. Montréal, les Éditions du Jour, coll. les romanciers du jour, 1970. 212 pages. (Réédition en 1972)

Les Apparences, tome III des Manuscrits de Pauline Archange, Montréal et Paris. les Editions internationales Stanké, coll. 10/10, 1981, 215 pages.

Dürer's Angel, translated by David Lobdell, Vancouver, Talon Books, 1976. 105 pages.

Dürer's Angel, translated by David Lobdell, Toronto. McClelland and Stewart, 1982. 105 pages.

Le Loup. Montréal, les Editions du Jour, coll. les romanciers du jour, 1972. 245 pages. 
Le Loup, Montréal et Paris, les Editions internationales Stanké, coll. 10/10, 1980. 255 pages. (Un extrait a paru dans le Devoir, vol. LXIII. n' 36 (12 février 1972),

p. 15, sous le titre: a Le Loup: I'amour des hommes et l'amour de son prochain -).

The Wolf, translated by Sheila Fischman, Toronto. McClelland and Stewart, 1974. 142 pages.

Un Joualonais, sa Joualonie. Montréal, les Editions du Jour, coll. les romanciers du jour, 1973, 300 pages.

A cour joual, Paris, Editions Robert Laffont, 1974, 300 pages.

Un Joualonais, sa Joualonie. Montréal et Paris, les Éditions internationales Stanké. coll. 10/10, 1979, 317 pages.

St. Lawrence Blues, translated by Ralph Manheim, New York, Farrar, Strauss and Giroux, 1975, 229 pages.

St. Lawrence Blues, translated by Ralph Manheim, New York, Bantam Edition, 1976, 203 pages.

St. Lawrence Blues, translated by Ralph Manheim, Londres, Harrap. 1977. 229 pages.

Manuscripts of Pauline Archange and St. Lawrence Blues, préface de Marie-Claire Blais. illustrations de Mary Meigs. Toronto. House of Exile, 1977, 161 pages.

Une liaison parisienne, Montréal, Editions Stanké/Quinze, 1975, 175 pages.

Une liaison parisienne, Paris, Editions Robert Laffont, 1976. 175 pages.

Une liaison parisienne. Montréal, Quinze Éditeur, 1980, 181 pages (postface de François Ricard).

Une liaison parisienne, Montréal et Paris, Éditions internationales Stanké, coll. 10/10, 1982, 173 pages.

A Literary Affair, translated by Sheila Fischman, Toronto, McClelland and Stewart, 1979, 160 pages.

Les Nuits de l'Underground, Montréal, les Editions internationales Stanké, 1978, 267 pages.

Nights in the Underground: An Exploration of Love, translated by Ray Ellenwood Toronto. General Publishing, 1979. 199 pages.

Nights in the Underground: An Exploration of Love, translated by Ray Ellenwood, Don Mills. Ontario, Musson Books Company. 1979, 199 pages.

Nights in the Underground: An Exploration of Love, translated by Ray Ellenwood, Toronto, General Publishing, coll. Pocket, 1982, 199 pages.

Le Sourd dans la ville. Montréal, Editions internationales Stanké, 1979, 214 pages.

Le Sourd dans la ville, Paris, Editions Gallimard, 1980, 200 pages.

Le Sourd dans la ville, Montréal, Editions du Club Québec-Loisirs, 1980, 214 pages.

Deaf to the City, translated by Carol Dunlop. Toronto, Lester, Orpen \& Dennys, coll. International Fiction List, 1980, 220 pages. (Rééditions en 1981 et 1982)

Visions d’Anna. Montréal, Editions internationales Stanké, 1982, 174 pages.

Visions d'Anna, Paris, Editions Gallimard, 1982.

\section{Thểtre}

Éléonor, pièce crèee par les comédiens de l'Estoc en novembre 1960, dans une mise en scène d'André Ricard. Manuscrit déposé à l'Université de Montréal, $49 \mathrm{f}$.

La Roulotte aux poupées, pièce créée par l'Atelier du Proscenium à Québec, à l'été 1960. Reprise à Montréal, au mois d'octobre de la même année. Présentée à Radio-Canada, le 13 mars 1967, dans le cadre des Beaux Dimanches (inédit).

Vivre dे deux parmi les autres, pièce inédite. 1968. 
L'Exécution, pièce en deux actes, présentée a Montreal, au Théâtre du Rideau Vert, en 1968.

L'Exécution. Piece en deux actes. Montréal, les Editions du Jour, coll. le théâtre du jour, 1968. 118 pages (réédition en 1970). (Un extrait. Acte premier, scéne I, parut dans la Presse. vol. LXXXIV. $n^{\circ} 65$ (16 mars 1968), p. 26.)

The Execution. translated by David Lobdell, Vancouver, Talon Books. 1976. 118 pages.

Le Disparu, pièce d'une heure, radiodiffusée à Radio-Canada, pour l'émission Premières, le 20 juillet 1971.

Un seigneur en province, pièce inédite, 1972.

L'Envahisseur, pièce d'une demi-heure radiodiffusée à Radio-Canada, pour l'émission la Feuillaison, septembre 1972.

Deux destins, pièce d'une heure radiodiffusée à Radio-Canada pour l'émission Premières, le 10 mai 1973.

Fièvre, pièce radiodiffusée à Radio-Canada, pour l'émission Premières, le 11 octobre 1973.

Fièvre et Autres Textes dramatiques. Montréal, les Editions du Jour, coll. le théâtre du jour, 1974, 228 pages ("L'Envahisseur", "Le Disparu *, *Fièvren, "Un couple" et $\alpha$ Deux destins*).

Sommeil d'hiver, pièce lue au Festival d'Avignon en aoùt 1974 (inédit).

Une autre vie, pièce radiodiffusée à Radio-Canada, pour l'émission Premières. le 26 septembre 1974 (inédit).

Un couple, pièce radiodiffusée à Radio-Canada, pour l'émission Premières, le 13 février 1975.

Une fermme et les Autres. pièce radiodiffusée a Radio-Canada, pour l'émission Premières, le 23 janvier 1976 (inédit).

L'Océan, téléthéâtre présenté à Radio-Canada en 1976, pièce représentant le Canada pour le prix Louis-Philippe Kammans.

L'Océan (suivi de) Murmures, Montréal, Quinze Editeur, 1977, 166 pages.

The Ocean, translated by Ray Chamberlain, in Exile, vol. IV, nos 3 \& 4 .

La Nef des sorcieres, « Marcelle *, pièce présentée par le Théâtre du Nouveau Monde, a Montréal, en 1976. Ecrite en collaboration avec Marthe Blackburn. Nicole Brossard, Luce Guilbeault. France Théorêt et Pol Peltetier.

La Nef des Sorcières, Montréal, Quinze Editeur, 1977, 80 pages.

L'Enfant-vidéo, pièce radiodiffusée à Radio-Canada, pour l'émission Scénario. en 1977 (inédit).

Murmures, pièce d'une heure radiodiffusée à Radio-Canada, pour l'émission Premières, le 9 septembre 1977.

Murmures (précédé de) rOcéan. Montréal, Quinze Editeur, 1977, 166 pages.

Murmures, translated by Margaret Rose. Canadian Drama/l'Art dramatique canadien, vol. V, $\mathrm{n}^{\circ} 2$ (Fall 1979), p. 281-293.

Journal en images froides. dramatique télévisuelle en quatre épisodes. présentée a la télévision de Radio-Canada en 1978, pour l'émission Scénario (inédit).

L'Exil, pièce d'une heure présentée à Radio-Canada, le 30 avril 1979, pour l'émission l'Escale, dans une réalisation de Madeleine Géròme.

aL'Exil». Liberté, \# 133, vol. XXIII, n 1 (janvier-février 1981). pp. 31-51,

Le Fantôme d'une voix. pièce d'une heure radiodiffusée a Radio-Canada, pour l'émission Premières, le 18 janvier 1980.

Le Printemps de Tchékov, pièce inédite, 1981.

Halte dans la forét. à paraitre en 1983. 
Récit

Les Voyageurs sacrés ou I'Invraisemblable Instant, Écrits du Canada français, vol. XIV (1962), p. 193-257.

Les Voyageurs sacrés, Montréal, HMH, 1966, 111 pages (Réédition en 1969).

Three Travelers (précédé de) The Day is Dark, translated by Derek Coltman, New York, Farrar, Strauss and Giroux, 1966, 183 pages.

\section{Podmes}

Pays voilés, préface de Charles Mueller, Québec, Editions Garneau, 1964, 47 pages. Pays voilés (suivi d') Existences, Montréal, les Éditions de l'Homme, 1967,87 pages. Pays voilés (suivi d') Existences. Montréal, les Éditions internationales Stanké, 1982. Existences. Québec, Editions Garneau, 1964, 51 pages.

Existences (précédé de) Pays voilés. Montréal, les Éditions de l'Homme, 1967, 87 pages.

Existences (précédé de) Pays voilés, Montréal, les Editions internationales Stanké. 1982.

\section{Autres écrits}

«Poemes*, Ecrits du Canada trancais, vol. V (1959), p. 173.

“Lettre à des lecteurs», Points de vue, vol. V. n 5 (janvier 1960). p. 2.

«Albert Camus*, Liberté, \#7, vol. II, n० 1 (janvier-février 1960), p. 53.

* Notre littérature mérite l'amitié *, le Devoir, vol. LI, $n^{\circ} 83$ (16 avril 1960), pp. 9 et 13.

* La naissance de l'homme*, le Devoir, vol. LI, no 125 (4 juin 1960), p. 9.

* La fin d'une enfance* (nouvelle), Chátelaine, vol. Il, n० 5 (mai 1961), pp. 43, 50, $52,55$.

«Une demi-heure avec Paul Claudel (texte radiophonique), animé par Paul Dupuis a la radio de Radio-Canada, le 6 fóvrier 1963.

"Grand-mère Antoinette, dans Un siecle de littérature canadienne, HMH, 1967. p. 463.

«Un chapitre inédit de Marie-Claire Blais», le Devoir (supp.), vol. LVIII, n 252 (31 octobre 1967), p. XIX.

«Un acte de pitié * (nouvelle), Liberté, vol. XI, $n^{\circ} 2$ (mars-avril 1969), pp. 47-59.

*Testament de Jean-Le Maigre à ses frères *, Liberté, vol. XIV, $n^{\circ} 3$ (mai-juin 1972), pp. 74-83.

a Montréal contemporain * (récit), Ecrits du Canada francais, n 41 (1978), pp. 9-21.

* Literature, Life and Anti-Life. (discours prononcé à Calgary), Aurora, Doubleday Canada Lid, 1979 (non vidi).

\section{Parutions à des émissions radio- ou télédiffusées}

Table ronde de trente minutes sur les Manuscrits de Pauline Archange, à l'émission Des livres et Des hommes, a la radio de Radio-Canada, le 5 novembre 1968.

Horizons, dans la série - Les jeunes auteurs», à la radio de Radio-Canada, le 26 avril 1972.

De face et De profil, à la radio de Radio-Canada, le 22 février 1973. Présentation de trois portraits féminıns dans l'ceuvre de Marie-Claire Blais. L'émission s'est poursuivie le 1er mars 1973.

Book-Club. à la radio de Radio-Canada, le 9 mai 1973. L'émission a été consacrée à l'cuvre de Marie-Claire Blais.

Un écrivain et son pays. à la radio de Radio-Canada, le 5 mai 1975. 
Le Francais d"aujourd'hui, à la télévision de Radio-Canada, le 8 juin 1975, commentaires et lecture d'Un Joualonais, sa Joualonie.

Book-Club. à la radio de Radio-Canada, le 2 février 1976, analyse et critique d'Une liaison parisienne.

Femme d'aujourd'hui, à la télévision de Radio-Canada, le 19 mars 1978, elle présente son roman les Nuits de I'Underground.

The Garden and the Cage, à la télévision de Radio-Canada (réseau anglais), documentaire sur Marie-Claire Blais et Gabrielle Roy, 1979.

Sel de la semaine, à la télévision de Radio-Canada, le 3 mars 1967.

\section{Filmographie}

Une saison dans la vie d'Emmanuel. adaptation cinématographique du roman, dans une réalisation de Claude Weisz, France, 1973.

Le Livre de chevet. court métrage de François Reichenbach, 1967.

Marie-Claire Blais, court métrage de Clovis Durand, Office du Film du Québec. 1972.

\section{Prix et titres}

Prix de la langue française, pour la Belle Béte. 1961.

Bourse Guggenheim, 1963-1964.

Prix France-Québec, a Paris, pour Une saison dans la vie d'Emmanuel, 1966, avec Claire Martin, Dans un gant de fer.

Prix Médicis, à Paris, pour Une saison dans la vie d'Emmanuel, 1966.

Prix du Gouverneur Général, à Ottawa, pour les Manuscrits de Pauline Archange (poésie), en 1969.

Ordre du Canada, à Ottawa, en 1975.

Docteur Honoris Causa, à Toronto, Université York, 1975.

Prix Belgique-Canada, à Bruxelles, pour son couvre, 1976.

Professeur honoraire, à Calgary, à la Faculty of Humanities, University of Calgary. 1979.

Prix du Gouverneur Général, à Ottawa, pour le Sourd dans la ville (roman). 1979.

Prix David, à Québec, pour l'ensemble de son cuvre, 1982.

\section{ETUDES}

\section{Cuvre en général}

(Anonyme), „Marie-Claire Blais a New York», Perspectives, vol. II, n० 47 (19 novembre 1960), pp. 18-20.

. Three Montrealers obtain Fellowships», The Gazette, vol. CXCVII, (March 31, 1965), p. 3.

- a Inauguration du Comptoir du livre au Centre d'Art", IArgenteuil, vol. XIV. $n^{\circ} 48$ (8 décembre 1965), p. 18.

—. «Profil de deux écrivains $*$, le Soleil, vol. $L X \mid X, n^{\circ} 170(18$ juillet 1966), p. 15.

(11 octobre 1966), p. 4.

- "La politique, la littérature et les arts ont été leurs charges d'actions*. le Soleil, vol. LXX. n० 1 (28 décembre 1966). p. 24.

- "Conférence de janvier . les Jeunesses littéraires du Canada trancais, vol. IV. $n^{\circ} 2$ (février 1967), p. 22. 
., "Le mythe d'une littérature», le Carabin, vol. XXVII, n 49 (28 mars 1967), pp. 5 et 12 .

_ـ_._. "Les écrivains québécois», Aujourd'hui Québec, vol. III, n³ (mai 1967). p. 14.

_. “Chàtelaine en pantoufles», Châtelaine, vol. VIII, n 9 (septembre 1967). p. 4.

"Marie-Claire Blais, une personne fort charitable», Dernière Heure, vol. 11. $n^{\circ} 50$ (3 septembre 1967), p. 21.

-_ "La bohème d'hier à Québec: Saint-Pierre, Vigneault, Blais, Roy=, la Semaine à Radio-Canada, vol. I, n 35 (25 novembre-1 er décembre 1967), p. 15.

- Les jeunes s'infiltrent dans tous les domaines $\%$, le Sud, vol. IV, $n^{\circ} 154$ (10 avril 1968), p. 21.

—. «Cuvres \#, Quill and Quire, vol. XL, n० 12 (December 1974), p. 19.

-, «Prix à Marie-Claire Blais», le Droit, vol. LXIV, n 31 (3 mai 1976), p. 21. . "Marie-Claire Blais reçoit le prix Belgique-Canada», le Soleil, vol. LXXX, n० 111 (6 mai 1976), p. D-5.

__. "Marie-Claire Blais dans le Larousse», le Journal de Montréal, 111 novembre 1980), p. 46 (non vid).

AHMED, Maroussia, "La technique de l'inversion dans les romans de Marie-Claire Blais». The Canadian Modern Language Review, vol. XXXI, n० 5 (May 1975). pp. 380-386.

ALLAIRE, Emilia-8., "Marie-Claire Blais et son rêve», la Revue populaire, vol. LIV, $n^{\circ} 2$ (février 1961), pp. 6-7, 20.

ARGUIN, Maurice. APortrait. Marie-Claire Blais», Quebec francais, n 22 (mai 1976), p. 11.

ATWOOD, Margaret, a Un petit rat heureux», le Maclean, vol. XV, $n^{\circ} 9$ (septembre 1975), pp. 19-21, 43. (A paru également en anglais, le mème mois dans Maclean's, vol. LXXXVIII, $n^{\circ}$ 9, pp. 26-29, sous le titre: a Marie-Claire Blais is not for burning $x$.)

AUBIN, Benoit, «Pour lire Marie-Claire Blais», I'Action, vol. LVII, $n^{\circ} 17$ (12 avril 19671 , p. 4.

AUSTIN. Paul-M., a La littérature québécoise d’après-guerre vue de Moscou», University of Toronto Quarterly, vol. XLIV, n० 1 (January-March 1974), pp. 114115.

BARDE, Jacqueline, «Les amours des mères et des amantes *, Elle, n 1326 (17 mai 1971), pp. $241-243$.

BASILE. Jean, x Les grands thèmes du roman canadien: la femme», Liberte, \#42. vol. VII, n 6 (novembre-décembre 1965), p. 536.

BEAULIEU, Michel, «Marie-Claire Blais qui vit à l'étranger pour prendre le 'recul nécessaire' nous rend une petite visite pour 'faire le plein', Perspectives. vol. XVI. $n^{\circ} 50$ (14 décembre 1974), pp. 10-12.

BEAUREGARD. Hermine, «De Maria Chapdelaine à Élaine Bédard „, Liberté, vol. VII. $n^{\circ} 4$ (juillet-août 1965), pp. 353-361.

- *'J'ai appris par-dessus la corde a linge' *, le Petit Journal, vol. XLI, $n^{\circ} 45$ (3 septembre 1967), p. 46.

BERNIER, Conrad, "L'offensive de nos romanciers", le Petit Journal, vol. XLI, $n^{\circ} 48$ (24 septembre 1967), p. 58.

BERNIER, Thérèse, «La composition littéraire chez Marie-Claire Blais», le Soleil, vol. LXXI, n63 (12 mars 1968), p. 31.

BLAIS, Jacques, « Notes sur le héros de roman québécois, de la Scouine à l'Hiver de force», Québec trançais, n 17 (février 1975). p. 37. 
BLOIS (pseudonyme), "Lettres et Arts. Une entrevue avec Marie-Claire Blais. Si ses romans sont tragiques, c'est que sa vision l'est aussi", le Petit Journal. vol. XL. $n^{\circ} 27$ (1er mai 1966), p. 38.

BOIVIN, Gérard-Marie, "Le monde étrange de Marie-Claire Blais ou la cage aux fauves», Culture, vol. XXXIX, n० 1 (mars 1968), pp. 3-17.

BOSQUET, Alain, “Entre psychologie et psychanalyse. Les révoltes de Marie-Claire Blais», le Monde, vol. XXVII, nº 155 (2 avril 1971), p. 18.

BOUFFARD. Odoric, "Le Canadien français entre deux mondes». Culture, vol. XXVIII, n 4 (décembre 1967), pp. 347-356.

BOURDET, Denise, a Marie-Claire Blais", la Revue de Paris, vol. LXXIV, $n^{\circ} 2$ (février 1967), pp. 129-136.

BOURQUE. Paul-André, "L'américanité du roman québécois», Études littéraires. vol. VIII, $n^{\circ} 1$ (avril 1975), pp. 17-18

BRAULT, Jacques, “Les grands thèmes du roman canadien $»$, Liberté, \#42, vol. VII, $\pi^{\circ}$ 6 (novembre-décembre 1965). pp. 539-540.

BRÙLĖ. Michel, "Introduction à l'univers de Marie-Claire Blais *, Revue de l'institut de sociologie (Bruxelles), vol. XLII, n० 3 (1969), pp. 503-513.

CALLAGHAN, Barry, *An Interview with Marie-Claire Blais*, The Tamarack Review. n०37 (Fall 1965), pp. 29-34.

CANTIN, Pierre, HARRINGTON, Normand et HUDON, Jean-Paul, Bibliographie de la critique de la littérature québécoise dans les revues des XIXe et XXe siècles. Ottawa, Centre de recherche en civilisation canadienne-française. 1979. 5 volumes, 1254 pages (pagination continue), (voir tome II, pp. 240-248).

CHAMBERLAND, Roger, a Libre conversation avec Marie-Claire Blais. Fragments d'elle-mèmen, Québec français, $n^{\circ} 43$ (octobre 1981), pp. 39.41.

CHÁTILLON, Pierre, a Marie-Claire Blais telle qu'en elle-méme», Livres et Auteurs canadiens, 1968. pp. 241-245.

CHÉNE, Yolande, aLes grands thèmes du roman canadien: la mortn, Liberté, \#42, vol. VII, $n^{\circ} 6$ (novembre-décembre 1965), p. 536.

CLOUTIER, Cécile, aL'homme dans les romans écrits par les femmes», Incidences, $n^{\circ} 5$ (avril 1964), pp. 9-12.

- - Panorama de la littérature québécoise aujourd'hui», The Canadian Modern Language Review, vol. XXXI. n 1 (October 1974), pp. 12-13.

DASSYLVA, Martial. ¿Une petite jeune fille toute simple», la Presse (supp.), vol. LXXXI. n० 141 (19 juin 1965). p. 1.

DAVID, Benoit, «Des enfants pour Marie-Claire Blais», Télé-radiomonde, vol. XXVIII, n० 47 (5 décembre 1966). pp. 6-7.

DELPECH, Jeannine, a Les enfants terribles du Québec», les Nouvelles littéraires, $n^{\circ} 2042$ (20 octobre 1966). p. 3.

DORION, Gilles, «a littérature québécoise 1960-1977. II. Le roman», Études francaises, vol. XIII, nos 3-4 (octobre 1977), pp. 317-319.

DUFRESNE, Georges. «Marie-Claire Blais visionnaire», Cité libre. vol, Xl, $n^{\circ} 33$ (janvier 1961), pp. 24-25.

ETHIER-BLAIS, Jean, aEntre femmes seules: Marie-Claire Blais», Signets II, Montréal, le Cercle du Livre de France. 1967. pp. 228-232.

FALARDEAU, Jean-Charles, «Brèves réflexions sur notre roman contemporain». Liberté, \#42, vol. VII, n 6 (novembre-décembre 1965), pp. 468-470.

- - Société canadienne et culture française. Colloque international organisé a l'Université de Liège le 31 janvier 1969x. Liège. les Congrés et Colloques de rUniversité de Liège, vol. LVI (1970). p. 32.

FABI, Thérèse, "Bibliographie. Marie-Claire Blais», Présence francophone, $n^{\circ} 4$ (printemps 1972), pp. 209-216. 
- le Monde perturbé des jeunes dans l'ceuvre romanesque de Marie.Claire Blais. Sa vie, son ceuvre, la crrtique (essai), Montréal, Éditions Agence d'Arc Inc. 1973, 193 pages.

FOLCH, Jacques, "Nous parlions de Salut Galarneau!n, Liberté, vol. IX, n० 5 (septembre-octobre 1967), pp. 68-70.

FRECHETTE, Jean, "Marıe-Claire Blais ou la pudeur de vivre». le Devoir (supplément littéraire), vol. LVIII, $n^{\circ} 251$ (31 octobre 1967), p. XX.

FREMONT, Gabrielle, "Marie-Claire Blais: au çeur de l'angoısse», Québec francais, $n^{\circ} 43$ loctobre 1981), pp. 41-43.

FRENCH, William, "Les femmes dans nos lettres", la Revue Imperial Oil, vol. LIX, $n^{\circ} 1$ (1975), p. 7. (A paru en anglais dans The Canadian Author and Bookman. vol. Ll, n० 3 (Spring 1976), pp. 6-7, sous le titre *The Women in our Literary Life $\times$.

GILLARD, Roger, “Connaitre Marie-Claire Blais", Marginales, n 112 (février 1967), pp. 56-60.

- «Marie-Claire Blais ou la révolte du roman canadien $*$, la Dryede, $n^{\circ} 50$ (été 1967). pp. 63-80.

GIRARD, Réal, *Marıe-Claire Blais, écrivain: les apparences de l'écrituren, Livres et Auteurs québécois, 1972, pp. 363-374.

GOLDMANN, Lucien, "Note sur deux romans de Marie-Claire Blais*, Revue de rinstitut de sociologie (Bruxelles), vol. XLII, $n^{\circ} 3$ (1969), pp. 515-523 (reproduit dans Structures mentales et Creation culturelle. Paris. Editions Anthropos, 1970, 493 pages (voir pages 401 -414) et dans Sociologie et litterature, recherches récentes et discussions. Bruxelles, Éditions de l'institut de sociologie, 1970. pp. 187-195.

GORDON, Jan B., \&An Incandescence of Suffering, the Fiction of Marie-Claire Blais:, Modern Fiction Studies, $n^{\circ} 22$ (1976), pp. 467-484.

HAMEL, Réginald, HARE, John et WYCZYNSKI, Paul, Dictionnaire pratique des auteurs québécois, Montréal, Éditions Fides, 1976, xxv, 723 pages (voir pages 67-69).

HAMELIN, Jean, a Une influence plus apparente que réelle», Liberté, \#42, vol. VII, n० 6 (novembre-décembre 1965). pp. 471-474.

KEATING, L. Clark, a Blais, French-Canadian Naturalist Romances Notes*, Chapel Hill, no 15 (1973), pp. 10-17.

KRAFT, James, « Fiction as Autobiography in Quebec. Notes on Pierre Vallières and Marie-Claire Blais», Novel, vol. VI, n० 1 (Fall 1972), pp. 73-78.

JASMIN, Claude, * Major, y aurait-y moven de placer un mot? *, le Petit Journal, vol. XXIX, n० 48 (8 août 1965), p. 26.

LABBE, Jean-Pierre, \& Marie-Claire Blais», Arts et Lettres (numéro spécial du Campus estrienl, avril 1968, pp. 10, 19.

LAMARCHE, Jacques-A., "La thématique de l'aliênation chez Marie-Claire Blais", Cité libre, vol. XVI, nos 88-89 (juillet-aoùt 1966), pp. 27-32.

LASNIER, Michelle, a Les quatre romancières de l'année. Pourquoi sont-elles en colère? », Châtelaine, vol. lil, n० 6 (juin 1962), pp. 30-32, 94-98, 101-102.

LE CLEC'H, Guy, «La critique intérieure de Marie-Claire Blais», les Nouvelles littéraires, $n^{\circ} 2268$ (11 mars 1971), p. 7.

LEDUC, Paule, aLe roman (1968)», Ėtudes littéraires, vol. II. $\pi^{\circ} 2$ (aoùt 1969), pp. 205-213.

LE GRAND. Albert, “Lettres québécoises: une parole enfin libérée», Maintenant, nos 68-69 (15 septembre 1967). pp. 267-272.

MAILHOT, Luce, "Humanisme de Marie-Claire Blass", le Devoir, vol. LVIII, n 79 (5 avril 1967). p. 5

MAJOR, André, "Ni ange ni bèten, le Devoir, vol. LVIII, nº 125 (29 mai 1967). p. 10. 
MARCEL, Jean (pseudonyme de Jean-Marcel PAQUETTE), "L'univers magique de Marie-Claıre Blais», IAction nationale, vol. LV, $n^{\circ} 4$ (décembre 1965). pp. 480.483

MARCOTTE, Gilles. "L'expérience du vertige dans le roman canadien-français». Écrits du Canada francais, vol. XVI (1963), pp. 229-246.

- "Les enfants de grand-mère Antoinetten. le Roman à l'imparfait. Essais sur le roman québécois d'aujourd"hui. Montréal, les Éditions la Presse Inc., coll. Échanges. 1976, pp. 91-137.

- "La dialectıque de l'ancien et du moderne chez Marie-Claire Blais. Jacques Ferron et Réjean Ducharme», Voix et images, vol. VI, n 1 (automne 1980). pp. 63-73.

MARMIER, Jean, « Le sabbat des enfants dans le roman québécois contemporain», Etudes canadiennes (Université de Bordeaux), vol. I, n 2 (1976). p. 25.

_, «Trois étapes d'une découverte: Bonheur d'occasion, Marie-Claire Blais. Réjean Ducharme. Antonine Maillet *. Lectures européennes de la littérature québécoise. Actes du colloque de Montréal (avril 1981). Montréal, Leméac. 1982, 388 pages (voir pages 108-139).

MARSHALL, Joyce. Three from the Other Nationn, The Tamarack Review, $n^{\circ} 46$ (Winter 1968), pp. 111-112.

MENARD, Jean, "Marie-Claire Blais», Archives des lettres canadiennes, tome I, Ottawa, 1961, p. 309 et tome II, 1962, p. 327.

MITCHAM, Allison. "The Canadian Matriarch: A Study in Contemporary French and English-Canadian Fiction". Revue de I"Université de Moncton, vol. VII. n० 1 (janvier 1974), pp. 38-42.

MOISAN, Clément, «Des littératures qui se font $"$ l'Ảge de la littérature (essai\}. Montréal, HMH, 1969, pp. 140-141.

MOREAU, Lise, "L'astrologie. Marie-Claire Blais \%, la Presse, vol. XCI, n 294110 décembre 1975), p. D-2.

MORRISSETTE, Brigitte, * Marie-Claire Blais. Un exil fécond s, la Patrie, vol. LXXXVIII, $n^{\circ} 2$ (15 janvier 1967), p. 75 .

MOS5. Sylvia, «Two years ago...., The Canadian Reader, vol. III, nº (April 1962), p. 10.

NACFAIRE, Jacqueline, aL'univers marin de Marie-Claire Blais», Protée, vol. I. n० 2 (avril 1971), pp. 85-88.

NADEAU. Vincent. Marie-Claire Blais: le noir et le tendre. Étude d'Une saison dans la vie d'Emmanuel suivie d'une bibliographie critique, Montréal, les Presses de l'Université de Montréal, coll. Lignes québécoises, 1974, 109 pages.

O'NEIL, Jean, "Quel est le meilleur lecteur de Marie-Claire Blais? *. la Presse (supp.), vol. LXXVIII, $n^{\circ} 76$ (13 janvier 1962), p. 8.

PARADIS, Suzanne. «La jeune fille écrivain: Marie-Claire Blais», le Devoir, vol. LIV, n० 146 (22 janvier 1963), p. 9.

- Femme fictive. Femme réelle. Le personnage féminin dans le roman féminin canadien-francais, 1884-1966. Québec. Editions Garneau, 1966, 330 pages (voir pages 176-197).

PERREAULT, Luc, a Quand Marie-Claire Blais rend visite au mairen, la Presse, vol. LXXXIII, n०2 (4 janvier 1967), p. 51.

PIAZZA, François. aMariè-Claire Blais: une montée solitairen, Montréal-Matin. vol. XLII, n²29 (20 février 1972), p. 17.

PILOTTE, Hélène, “ Marie-Claire Blais, l'insoumise des lettres canadiennes», Châtelaine. vol. VII. $n^{\circ} 8$ (août 1966), pp. 21-23, 51-54.

PONTAUT, Alain, a La littérature n'est-elle qu'un fait socıal? (Entrevue avec Lucien Goldmann)m. la Presse (supp.), vol. LXXXIII, n³5 (11 février 1967), p. 6. 
"L'idéologie natıonaliste de G. Roy et M.-C. Blais". la Presse (supp. "Ans et Lettres"), vol. LXXXIII, $n^{\circ} 57$ (11 mars 1967), p. 4.

RACICOT, Ginette, "Place aux femmes». Vie et Carrière, vol. III, n 9 (mai 1968), p. 15.

RASPA. Anthony (pseudonyme), "Epic Blais in Translation», Journal of Canadian Fiction, $n^{\circ} 19$ (1977), pp. 138-140.

RENAUD, André, "Romans, nouvelles et contes 1960-1965», Livres et Auteurs canadiens, 1965, pp. 7-12.

ROUSSEAU, Louis, "Le roman: un miroir de notre vécu religieux», Communauté chrétienne, vol. VI, n 36 (novembre-décembre 1967), pp. 456-467.

ROUTHIER, Benoit, "Le 'noir' des romans de Marie-Claire Blais", le Soleil, vol. LXX, n. 260 (2 novembre 1967 ), p. 35.

RUSSELL, George, "Nightmare's Child», Weekend Magazine, October 23, 1976. p. 11.

SIROIS, Antoine, "Le roman canadien-français, miroir de la société», Arts et Lettres (numéro spécial du Campus estrien), avril 1968. p. 4.

SMITH. Donald, “Les vingt années d'écriture de Marie-Claire Blais*, Lettres québécoises. $n^{\circ} 16$ (hiver 1979-1980), pp. 51, 53-58.

STOUK. David, «Notes on the Canadian Imagination», Canadian Literature, $n^{\circ} 54$ (Autumn 1972), pp. 9.26.

STRATFORD, Philip, Marie-Claire Blais, Toronto, Forum House, coll. Canadian Writers \& their Works, 1971. 70 pages.

SYMONS, Scott, «es lettres. Marie-Claire Blais: l'autopsie du Québec aux yeux d'un Torontois», la Presse, vol. LXXVII, n 107 (18 février 1961), p. 24.

VACHON, Georges-André, « L'espace politique et social dans le roman québécois *. Recherches sociographiques, vol. VII, $n^{\circ} 3$ (septembre-décembre 1966), pp. 259-279.

VENNE, Rosario, «Une littérature à bon marché, l'Écho du Nord, vol. XXXI, $n^{\circ} 49$ $(21$ juin 1967). p. 60.

WADDINGTON, Miriam, « Chacun sa Blais $*$, Books in Canada, vol. III, $n^{\circ} 7$ (November 1974). pp. 3-5.

WILSON, Edmund, "Marie-Claire Blais", O Canada. An American's Notes on Canadian Culture», New York, Farrar, Strauss and Giroux, 1964, pp. 147-157.

WYCZYNSKI, Paul, «La littérature dans I'horizon de ses valeurs véritables *, le Quartier latin, vol. XLII, n 39 (27 février 1962), pp. 2-4.

\section{Theses}

ALLEN, Margaret, a Le problème du mal chez Bernanos et Marie-Claire Blais», mémoire de maitrise ès arts. Edmonton, University of Alberta, 1970.

ARGUIN, Maurice, «Les insoumis dans l'couvre de Marie-Claire Blais», mémoire de licence ès lettres, Québec, Université laval, 1968.

BEATON, Nancy, "La vision gothique de la survie dans les ceuvres de Marie-Claire Blais. Anne Hébert. Carson McCullers et Flannery $\mathrm{O}^{\prime}$ Connor $\%$ mémoire de maîtrise ès arts, Montréal, Université de Montréal, 1974.

DUMONT, Marıe-Marthe, «Univers romanesque de Marie-Claire Blais», mémoire de licence ès lettres, Québec. Université Laval, 1968.

FRECHETTE, Jean, "Thèmes et style dans I'œuvre de Marie-Claire Blais», mémoire de maîtrise ès arts, Montréal, McGill University, 1968.

GODIN, Azade, "Le désespoir de vivre dans l'ceuvre de Marie-Claire Blais», mémoire de maitrıse ès arts, Montéal, McGill University, 1969.

GREISS. Roger, "Le temps dans l'ceuvre romanesque de Marie-Claire Blais". mémoire de maitrise ès arts, Trois-Rivières. Université du Québec à TroisRivıères, 1973. 
HAYWARD. Annette-Marie, "L'univers des insoumıs dans l'cuvre de Marie-Claire Blaıs» mémoire de maitrıse ès arts, Halifax, Dalhousie Unıversity, 1968.

MACFARLANE, Ruth Evans, “Le rôle de la solitude dans le roman canadien-français de 1945 à 1965 \%. mémoire de maitrise ès arts. Fredericton, Unıversity of New Brunswick, 1969.

SAHEB. Arlette, "Iranie, dire et vouloir-dire chez Roch Carrier, Marie-Claire Blais et Réjean Ducharme», thèse de doctorat ès lettres. Montréal, Université de Montréal, 1979.

SAINT-PIERRE, LouIse D., "Les enfants et les adolescents dans l'œuvre de MarieClaire Blais», mémoire de maitrise ès arts. Edmonton, University of Alberta, 1969.

TREMBLAY, Roger, a La description des personnages dans l'œuvre romanesque de Marie-Claire Blais jusqu'en 1968», mémoire de maitrise ès arts, Sherbrooke, Université de Sherbrooke, 1968.

TREMBLAY, Victor-Laurent, «La révolte contre le patriarcat dans l'œuvre de Marie. Claire Blais", mémoire de maitrise ès arts, Vancouver. University of British Columbia, 1980.

URBAS, Jeannette, "Le personnage féminin dans le roman canadien-français de 1940 à $1967 n$, thèse de doctorat en philosophie (Ph. D.). Toronto, University of Toronto. 1971.

\section{ETUDES PARTICULIERES}

\section{La Belle Bête}

(Anonyme), “La Belle Bête», le Devoir. vol. L, n² 250 (24 octobre 1959), p. 9. , aMad Shadows:, The Vancouver Sun. October 15, 1960 (non vidf).

. "First Novel brings Literary Storm», Journal Sioux City (lowa), August 21. 1975 (non vidh).

—_. «Mad Shadows», Sun Lewiston Auburn, October 18, 1960 (non vidi).

- _. «La Belle Bête, à déconseiller", Libre Belgique, 6 juillet 1961, p. 10 (non vidi).

ASSELIN, Suzanne, Mad Shadows: ceuvre monumentale d'après un roman de Marie-Claire Blais», la Presse, vol. XCIII, n 229 (26 septembre 1977), p. C-8 (à propos de l'adaptation chorégraphique).

BÉGIN, Monique, a J'ai lu... la Belle Bête de Marie-Claire Blais», le Quartier latin. vol. XLII, $n^{\circ} 20$ (24 septembre 1959), p. 5.

BICKERSTAFF, Isaac, «Mad Shadows (...) Swamp Angel. Marie-Claire Blais», Books in Canada. vol. II, n० 3 (July-September 1973), p. 54.

BIRNMAUM, Phyllis, «The Canadian Cadre - Mad Shadows», Book Marks, June 1976 (non vid).

BLOUIN, Yyon, "La Belle Bête... défiguréen, le Carabin, vol. XIX, n० $10(17$ novembre 1959), p. 4.

BOYER, Gilles, “Les idées et les livres. La Belle Bête», le Soleil, vol. LXXVIII, nº 265 (9 novembre 1959), p. 4.

DAGENAIS, Angèle, "Le Ballet National dans une cuvre de Marie-Claire Blais», le Devoir, vol. LXIX, n²22 (26 septembre 1977), p. 14 (a) propos de l'adaptation chorégraphique). 
D'ANJOU. Joseph, "Marie-Claıre Blais. La Belle Bête", Relatıons, n 229 (janvier 1960), p. 22 (reproduit dans Notre Temps, vol. XV. n $14(16$ janvier 1960). p. 10).

DAVIES, Robertson, "Schoolgirl shows in Young Writer's Book», The Winnipeg Tribune. (October 10. 1960) (non vidi).

, "The Schoolgirl Talent of Marie-Claire Blass", The Montreal Star, vol. XClI. $n^{\circ} 237$ (October 8, 1960), p. 27.

DAVIS. Marilyn-I., "La Belle Bête. Pilgrim unto Life». The Tamarack Review, $n^{\circ} 16$ (Summer 1960), pp. 51-59.

DESY, Pierrette, "A propos de la Belle Bête», le Carabin, vol. $X \mid X, n^{\circ} 8$ (3 novembre 1959), p. 3.

- "Les jeux interdits de Escojido-Paquet., le Carabin, vol. XIX, n० 10117 novembre (1959), p. 4.

DUHAMEL, Roger, a La vie des lettres. Le premier roman de Marie-Claire Blais impose son nom dans les lettres canadiennes*. la Patrie (du dimanche), vol. XXV, $n^{\circ} 52$ (27 décembre 1959). p. 34 (reproduit dans MARCOTTE, Gilles (compilateur). Présence de la critique. Critique et Littérture contemporaine au Canada français. Montréal, HMH, 1966, pp. 60-61).

ESCOJIDO, André et PAQUET, Gilles, Arts. Marie-Claire Blais. La Belle Bête». le Carabin, vol. XIX, n० 8 (3 novembre 1959), p. 6.

ETHIER, Jean-René, a Notes critiques. La Belle Báten, Monde nouveau, vol. XXI, n० 7 (19 décembre 1959), pp. 162-164.

ÉTHIER-BLAIS, Jean, "Les carnets de Jean Éthier-Blais*, le Devoir, vol. LXX, $n^{\circ} 76$ (31 mars 1979), p. 24.

FOURNIER. Guy, Un univers nourri de monstres», Perspectives, vol. II, $n^{\circ} 1$ (2 janvier 1960), pp. 6-7.

FOURNIER, Louise, “Marie-Claire Blais", Actualité ma paroisse, janvier 1960, p. 11.

GAGNON, Micheline, « Rencontre... la Belle Bête», le Carabin, vol. XIX, no 7 (27 octobre 1959), pp. 6-7.

GAUVREAU. Marjorie S., "La Belle Bóte. Marie-Claire Blais", Liberté, \#6, vol. I, n० 6 (novembre-décembre 1959). pp. 414-416.

GAY, Paul, a La Belle Bête», le Droit, vol. XLVII, n² 259 (7 novembre 1959), p. 17.

GERSH, Gabriel, "Mad Shadows», The Dalhousie Review, vol. XLI, n 4 (Winter 1962), pp. 477, 479.

GILLARD, Roger, aMarie-Claire Blais: la Belle Bête», Marginales (Bruxelles), nos 110-111 (décembre 1966), pp. 112-114.

GOSE, Elliot, "Books in Review. The Witch within., Canadian Literature, n० 17 (Winter 1961), pp. 72-74.

KATTAN, Naïm, "La Belle Bête de Marie-Claire Blais», Cuiture, vol. XXXII, n 1 (mars 1971), pp. 400-404.

KIRKLAND, Bruce, «A Crazy Lady creates Ballet from Emotion», The Toronto Star. February 12, 1977 (non vidi) (à propos de l'adaptation chorégraphique).

KIRKWOOD. Hilda, "Mad Shadows», Canadian Forum, vol. XL (February 1961), p. 264 (non vidi).

LARUE-LANGLOIS, Jacques, "La Belle Bête», le Devoir, vol. LXXIII, n 83 (10 avril 1982), pp. 24, 26.

LECLERC, R(ita), *La Belle Bête de Marie-Claire Btais», Lectures, vol. VI, $n^{\circ} 7$ (mars 1960), pp. 202-203.

LEGARÉ, Romain, «Blais, Marie-Claire: la Belle Bête», Culture, voi. XXI, n० 1 imars 1960), p. 99.

LEPAGE, Yvan-G., “Sicut enim Narcissus: la Belle Bête de Marie-Claire Blais». Coincidences, vol. IV, nos 2-3 (mai-décembre 1980), pp. 101-108.

LINZE, Georges, “Marie-Claıre Blais: la Belle Bête», le Soir (Belgıque), 3 août 1961. p. 8 (non vidh). 
LOMBARD, Pierre (pseudonyme de Pierre-Paul TURGEON), "Vos lectures. La Belle Bête". l"Action catholique. vol. LII, n० 16132 (12 décembre 1959). p. 4.

MAHER, Gilles, "Les autres qui ont une vie à vivre, tout comme nous. Marie-Claire Blais. La Belle Bêten, le Quartier latın. vol. XLII, $n^{\circ} 30$ (26 janvier 1960), p. 5.

MARCOTTE, Gilles, "La vie des lettres. Marie-Claire Blais, romancière et poète. La Belle Bêten. le Devoir, vol. L. n² 256 (31 octobre 1959), p. 11.

- "Books in Review. Une romancière de vingt ans. Marie-Claire Blais. La Belle Bête», Canadian Literature. n० 3 (Winter 1960), pp. 71-72.

MOREAU, Gérald, "Le rêve et le réalisme dans la Belle Bête de Marie-Claire Blais». Revue de l'Université d'Ottawa, vol. XLII, n० 4 (octobre-décembre 1972), pp. 570-574.

MOSS, John, A Reader's Guide to the Canadian Novel, Toronto, McClelland and Stewart, 1981, 399 pages (voir pages 299-300).

NADEAU, Vincent, ‘la Belle Bête, roman de Marie-Claire Blais , dans Dictionnaire des ceuvres littéraires du Québec. tome III: 1940-1959. sous la direction de - Maurice Lemire, Montréal, Fides, 1982, pp. 118-120.

PARE, Jean, "La vie littéraire. Deux romans canadiens. La Belle Bête", la Presse, vol. LXXVI, n० 45 (5 décembre 1959), p. 38.

PATRIDGE, John J., « Macabre Existences», The Visitor, May 5, 1961 (non vidi).

PHILIPP. Roland, aFantasmal Fury», The Montreal Gazette. vol. CLXXXIII (October 15, 1960), p. 14.

ROBILLARD, Jean-Paul, «Marie-Claire Blais: a 19 ans, elle entre en coup de vent dans notre littérature...!. , le Petit Journal, vol. XXXIV, $n^{\circ} 1$ 11er novembre 1959). p. 102.

S., M., "Élogieux commentaires sur le talent de Marie-Claire Blais». la Presse, vol. LXXXVI, $n^{\circ} 14$ (30 octobre 1959). p. 18.

SÉRAFIN. Bruce. *Marie-Claire Blais, la Belle Bête», Essays on Canadian Writing. nos 7-8 (Fall 1977), pp. 63-73.

URBAS, Jeannette, « Reflet et révélation. La technique du miroir dans le roman canadien-francais moderne», Revue de r'Université d'Ottawa, vol. XLIII, $n^{\circ} 4$ (octobre-décembre 1973), pp. 573-586 (voir pages 576-577).

WAELTI-WALTERS, Jennifer, «Beauty and Madness in Marie-Claire Blais' la Belle Bête», Journal of Canadian Fiction, nos 25-26 (1979), pp. 186-198.

\section{Tête blanche}

(Anonyme), \&e Salon du Livre présente un roman de Marie-Claire Blais, Tête blanchex, le Carabin, vol. XX, n 5 (27 octobre 1960), p. 4.

- ¿Les livres. Téte blanche par Marie-Claire Blais», Bulletin du Cercle juif. vol. VII. n 60 (décembre 1960). p. 3.

- "Tête blanche», le Droit, (10 mai 1967), p. 7 (non vidj).

BEAUDOIN, André, aArts. Tête blanche: roman de l'attenten, le Carabin. vol. $\mathrm{XX}$, $n^{\circ} 13$ (15 décembre 1960), p. 8.

BELLEAU, André, a Roman populaire et statuette romantiquen, Liberté. H 13, vol. III, $n^{\circ} 1$ (janvier-février 1961), pp. 452-455.

pp. 478-480 (à propos de l'échange de lettres entre Jacques Godbout et Scott Symons, dans la Presse, tes 7, 11, 18 et 25 mars 1961, sur Téte blanche).

CLOUTIER. Cécile, "L'homme dans les romans écrits par des femmes", Incidences, $n^{\circ} 5$ (avril 1964), pp. 9-12 (voir page 9).

D'ANJOU, Joseph, "Les livres. Marie-Claire Blais: Téte blanchen, Relations, n०240 (décembre 1960), p. 334. 
DUFRESNE, Georges, "Marie-Claire Blais visionnaire», Cité libre, vol. XI, $n^{\circ} 33$ (janvier 1961), pp. 24-25.

LEGARE. Romaın, «Marı-Claire Blais: Tête blanche», Culture, vol. XXII, no 1 (mars 1961). pp. 114-115.

LE MOINE, Roger, «Arts. Tête blanche», le Carabin, vol. XX. n० 14 (22 décembre 1960), p. 9.

LOCKOUELL, Clément, "Tête blanche de Marie-Claire Blais», le Devoir, vol. LI. $n^{\circ} 260$ (12 décembre 1960). p. 11

PARE. Jean, "La vie littéraire. Deux romans de l'enfance solitaire. Tête blanche ", la Presse. vol. LXXVII, n 31 (19 novembre 1960), p. 22.

\section{Le Jour est noir}

(Anonyme), *Les Éditions du Jour», le Quartier latin, vol. XLIV, n 48 (29 mars 1962), p. 2.

- "Les livres. Le Jour est noir, par Marie-Claire Blais», Bulletin du Cercle juif, vol. VIII, $n^{\circ} 72$ (mars 1962), p. 2.

- «On réédite à Paris deux romans de Marie-Claire Blais*, le Droit, vol. LIX, $n^{\circ} 12$ (10 avril 1971), p. 31 .

BARBEAU, Victor, la Face et l'Envers. Essais critiques, Montréal, les Publications de l'Académie canadienne-française, 1966, 158 pages (voir pages 48-50).

BERCOFF, André, «Le désespoir par deux», l'Express, n 1033 (26 avril - 2 mai 1971). p. 135.

BERGER, Yves, « Le néant et l'infini: les nouveaux livres: le Jour est noir et /'Insou. mise ", le Figaro littéraire, n०1291 (15 février 1971), p. 20 (reproduit en guise de préface au roman publié chez Grasset).

BLOUIN, Suzanne, « Les arts et les lettres. Le Jour est noir», le Carabin, vol. XXI, $n^{\circ} 21$ (22 février 1962), p. 11.

BOURQUE, Paul-André, * Marie-Claire Blais. Le Jour est noir suivi de I'Insoumise ", Livres et Auteurs québécois, 1979, pp. 26:27.

BOYER, Gilles, Marie-Claire Blais pareille à elle-même», le Soleil, vol. LXXXI. $n^{\circ} 44$ (17 février 1962), p. 4.

D(ALLAIRE), H(enri), «Arts et lettres. Livres», Maintenant, vol. I, $n^{\circ} 5$ (mai 1962). p. 194.

DAVIES, Robertson, «Elegant Egoists. The Day is Dark and Three Travelers», New York Times Book Review, April 30. 1967, p. 4.

GAUGEARD, Jean, *Tendresses funèbres. Lettres françaises, n० 1381 (14-20 avril 1971), p. 3.

HAMELIN, Jean, *De Gilles Marcotte et de Marie-Claire Blais», le Devoir, vol. LIII. $n^{\circ} 40$ (17 février 1962), p. 11.

LEBLANC, Gérald-D., aL'univers mythique du Jour est noir de Marie-Claire Blais". Revue de l'Université de Moncton, vol. VIII, n 2 (mai 1975), pp. 17-22.

LEROUX, Georges, a Le Jour est noir , le Sainte-Marie, 2 mars 1962, p. 9.

MAILHOT, Michèle A., "L'homme en face de la vie». Châtelaine, vol. IIl, $n^{\circ} 6$ (juin 1962), p. 52.

MARCOTTE, Gilles, aLes livres. Le troisième roman de Marie-Claire Blais», la Presse, vol. LXXVIII, no 100 (10 février 1962), pp. 8-9.

MÉNARD, Jean, «La vie littéraire. Le Jour est nair», le Droit, vol. L, $n^{\circ} 47$ (24 févrıer 1962). p. 12.

PARADIS, Suzanne, "Lien du passé et de l'avenir", le Devoir, vol. LIV, $n^{\circ} 151$ (29 juin 1963), p. 9.

PARE, Jean, «Le Jour est noir, roman par Marie-Claire Blais. Une recette de fantôme s, le Nouveau Journal (supp.), vol. I, nº 152 (3 mars 1962), p. 111. 
RENAUD, André, "Le Jour est noir de Marie-Claire Blais", Livres et Auteurs canadiens, 1962, pp. 8-9.

RICHER. Julia, "Le Jour est noir". Notre Temps, vol. XVII, n 17 (24 lévrier 1962), p. 5 .

TARDIF, Jacques. "Romanciers canadiens-français. Le Jour est noir de Marie-Claire Blais», le Quartier latin, vol. XLIV, $n^{\circ} 41$ (6 mars 1962), p. 5.

Theses

HAUSSMAN, Chantal, "Quelques approches de la critique devant le Jour est noir". mémoıre de maitrise ès arts. Vancouver, Universiry of British Columbia. 1973.

LEBLANC, Gérald-D. "Thèmes, structure et signification dans le Jour est noir de Marie-Claire Blais", mémoire de maitrise ès arts. Moncton, Université de Moncton, 1974.

\section{Une saison dans la vie d'Emmanuel}

(Anonyme), "Un nouveau roman de Marie-Claire Blais», le Devoir, vol. LVI, n० 143 (19 juin 1965), p. 10.

—, aLire, lire, lire, lirem, le Oroit, vol. LIII, $n^{\circ} 156$ (17 juillet 1965), p. 4.

*Les livres. Une saison dans la vie d'Emmanuel, par Marie-Claire Blais*. Bulletin du Cercle juif, vol. VI, n० 106 (octobre 1965), p. 3.

-. aMarie-Claire Blais publiée chez Grasset». la Presse (supp.). arts et lettres*), vol. $L X X X \mid 1, n^{\circ} 65$ (19 mars 1966), p. 2.

-, "Télégrammes", Paris Match, 19 mars 1966, p. 41 (non vidi).

- Marie-Claire Blais et Claire Martin: prix France-Québec, 1966», le Devoir. vol. LVII, $n^{\circ} 77(2$ avril 1966), p. 11.

- "L'enfer de Marie-Claire Blais décrit par un critique parisien ", la Patrie, vol. LXXXVII, $n^{\circ} 19$ (15 mai 1966), p. 68.

(12 juillet 1966), p. 2.

___ "Blais, Marie-Claire, Une saison dans la vie d'Emmanuel $\%$, Bulletin critique du livre français, vol. XXI, nos 8-9 (aoūt-septembre 1966), p. 690.

- _. Une romancière québécoise gagne un des plus grands prix littéraires français ", le Journal de Montrésl. vol. III, n 137 (29 novembre 1966), p. 28.

- , Le Prix Femina à Irène Monesi et le Médicis à Marie-Claire Blais», le Combat. vol. XXIV, n० 6980 (29 novembre 1966). p. 9.

- Les jurys ont couronné deux femmes: le FEMINA à Irène Monesi pour Nature morte devant lo tenêtre. le MEDICIS à Marie-Claire Blais pour Une saison dans la vie d'Emmanuel». la Metropole (Anvers), 29 novembre 1966. (non vidi).

_- Pour son roman Une saison dens la vie d'Emmanuel, Marie-Claire Blais obtient le prix Médicis à Paris», le Devoir, vol. LVII, n 277 (29 novembre 1966), p. 8 (reproduit dans The Quebec Chronicle-Telegraph, vol. CCIII, $n^{\circ} 136$ (November 29, 1966), p. 6. sous le titre: a Psychological Study wins Top French Women's Awardn, et dans le Soleil, vol. LXIX, n'283 (29 novembre 1966). p. 12, sous le titre: a Appréciation de Une saison dans la vie d'Emmanue/s).

- Le Prix Médicis (attribué au 6e tour) a Marie-Claire Blais*. le Parisien libéré, 29 novembre 1966 (non vidi).

- a Femmes écrivains à l'honneur à Paris. Irène Monesi obtient le prix Femina. Le prix Médicis est décerné à la Canadienne Marie-Claire Blais», la Libre Belgique, 29 novembre 1966 (non vidi).

—, «Le Canada enfin», le Devoir, vol. LVII, n² 278 (30 novembre 1966), p. 15.

-_. a Commentaires sur la littérature canadienne-française», le Soleil, vol. LIX, $n^{\circ} 284$ (30 novembre 1966), p. 42. 
"La presse française fait l'éloge de la littérature", le Droit, vol. LIV, n 207 (30 novembre 1966), p. 23.

- Marie-Claire Blais. Remerciements simples et confus à ses jurés», I"Action, vol. LIX, n० 17826 (30 novembre 1966), p. 19.

- a Née dans un quartier populaire de Québec $\bowtie$ I'Action, vol. LIX, n 17826 (30 novembre 1966), p. 19.

- «Prix Femına sous l'influence de Freud. Prix Médicis: hommage au Canadaw. Carrefour. 30 novembre 1966, p. 18 (non vidi).

-, aMarie-Claire Blais, le prix Médicis», IInterrogation, vol. XXXVIII, n 1 (décembre 1966), p. 14.

- a Assagnati i premi 'Foemina' o 'Medicis'. II Cittadina Canadese, vol. XXXVI, n० 48 (2 décembre 1966). p. 21 (non vidi).

- "Une saison dans la vie d'Emmanuel. Le prix Médicis: un roman noir", le Droit, vol: LIV, $n^{\circ} 210$ (3 décembre 1966), p. 7.

-, «Le Médicıs», Photo-Éclair, vol. I, n 10 (9 décembre 1966), p. 29.

, « Marie-Claire Blais obtient le prix Médicis à Paris $»$, le Courrier de Lavio-

lette, vol. XV, n० 34 (15 décembre 1966). p. 95 (reproduit dans IAppel, vol.

XXII, n० 17 (15 décembre 1966), p. 7).

- a Marie-Claire Blais, le prix Médicis», I'Interrogation, vol. XXXVIII, n

(21 décembre 1966), p. 14.

- a Marie-Claire Blais au Sel de la semaine», la Tribune, vol. LVII, n 258 (29 décembre 1966). p. 8.

- "Our Centennial speaks Volumes", The Montreal Star, vol. XCVIII, n 305 (December 31, 1966), p. 2.

- «Marie-Claire Blais. Une saison dans la vie d'Emmanue/». Commission de lecture de la J.I.C.F., XXIVe série, 3e fascicule (1967). pp. 1-5.

-Une petite Canadienne...*, la Patrie. vol. LXXXVIII, n 1 (1er janvier 1967). p. 21.

- "Marıe-Claire Blais et François Reichenbach au Sel de la semaine», le Journal de Montréal, vol. III, n' 165 (3 janvier 1967), p. 15.

- "Ces maudits Français". IÉcho abitibien, -vol. XIII, $n^{\circ} 10$ (8 février 1967), p. 23.

- "L'Avalée et Une saison en tète de liste», la Presse (supp. «Arts et lettres»). vol. LXXXIII, n²9 (11 février 1967), p. 2.

- "Family Feelings", The Times Literary Supplement, vol. LXVI, n 3396 (March 30, 1967), p. 272.

- "Une saison dans la vie d’Emmanuel (Prix Médicis 1966).. Rythmes et Couleurs, vol. XIII, $n^{\circ} 58$ (avril-juin 1967), pp. 35-36.

- - a Le feu d'artifice du roman canadien en France parait s'être éteint pour le moment». la Presse, vol. LXXXIII. n 75 (1er avril 1967), p. 42.

- , ¿L'Italie et I'Action jugent Marie-Claire Blais et son roman», le Devoir, vol. LVIII, n० 76 (ler avril 1967). p. 14.

-_. "Marıe-Claire Blais, nouvelle Gabrielle Roy pour les Français», Ia Presse. vol. LXXXIII, n० 78 (2 avril 1967). p. 2.

- " Marie-Claire Blais : dénoncer le monde homicide *, le Monde (supplément littéraire), vol. XXIV, $n^{\circ} 6914$ (5 avril 1967). p. V.

-_, "Blunt Edge of Tragedy". Newcastle Journal, April 8, 1967 (non vidi).

—_ "Child of an Old Darkness", Liverpool Daily Post, April 26. 1967 (non vidi).

, "Un Marie-Claire Blais publié a Paris et a Montréal », la Presse, vol. LXXXIV.

n० 215 (14 septembre 1968), p. 26.

- "Une saison dans la vie d'Emmanuels, Vient de paraître, vol. $\mathrm{IX}, \mathrm{n}^{\circ} 2$ (juin 1973), p. 26 (à propos de l'adaptation cinématographique). 
"Second festival de théâtre étudiant organisé par l'AORTE», le Oroit. vol. LX, n० 17 (15 avril 1972), p. 20 (à propos de l'adaptation théâtrale).

AFP, "La Canadienne Marie-Claire Blais décroche le prix Médicis", le Nouvelliste. vol. LXVII, $n^{\circ} 25$ (29 novembre 1966), p. 8.

AFP. "Le nom de Marre-Claire Blais dans tous les journaux parisiens", la Presse. vol. LXXXII, n०228 (30 novembre 1966), p. 91.

AFP, "Marie-Claire Blais, une révélation canadiennen, le Nouvelliste, vol. XLVII, n०26 (30 novembre 1966), p. 10.

AFP, "C'est un tendre petit oiseau tombé du nid", le Nouvelliste, vol. XLVII, $n^{\circ} 26$ (30 novembre 1966), p. 10.

AFP, "Une romancière canadienne obtient le prix Médicis", IÉvangéline, vol. LXXIX, $n^{\circ} 279$ (1er décembre 1966), p. 4.

AFP, “Marie-Claire Blais a reçu le prix Médicis», lÉvangile, vol. LXXIX, n 279 (1er décembre 1966), p. 8.

AFP. «Réception offerte par Vallerand en I'honneur de Marie-Claire Blais», le Nouvelliste, vol. XLVII, $n^{\circ} 28$ (3 décembre 1966), p. 26.

AFP. “A Paris, débat sur la littérature québécoise», la Presse, vol. LXXXII, $n^{\circ} 239$ (13 décembre 1966), p. 50.

AFP, aMarie-Claire Blais est une voix littéraire authentique», le Nouvelliste, vol. XLVII. $\pi^{\circ} 37$ (13 décembre 1966), p. 9.

ALLARD, Jacques, a Le roman québécois des années 1960 à 1968\%, Europe, vol. XLVII, nos 478-479 (février-mars 1969), pp. 41-50.

ALTER. Jean V.. "Cabanis, José, la Bataille de Toulouse (...) Blais, Marie-Claire: Une saison dans la vie d'Emmanuelı, The French Review, vol. $\mathrm{XL}, \mathrm{n}^{\circ} 5$ (April 1967), pp. 731-733.

AMOZARA, $M$. ., "Une saison dans la vie d'Emmanuel», Initiatives, vol. $X X \mid, n^{\circ} 2$ (décembre 1966), p. 20.

ANDERSON, Patrick, "Pity and Terror», The Spectator, vol. CCXVIII, no 7241 (April 7, 1967), pp. 395-396.

ANDERSON, Margaret, "The Church in Marie-Claire Blais' A Season in the Life of Emmanue/n, Sphinx, vol. II, n 3 (Winter 1976), pp. 40-45.

AQUiN, Hubert, a Nos cousins de Francen, Liberté, \# 49, vol. IX, $n^{\circ} 1$ (janvier-février 1967). pp. $76-78$ (a également paru dans Point de fuite, Montréal, le Cercle du livre de France. 1971, 159 pages (voir pages 67-70)).

ARNOTHY. Christine, "Une révélation canadienne: Une saison dans la vie d'Emmanuel par Marie-Claire Blais», le Parisien libéré, 19 avril 1966 (non vidi).

AUBIN, Benoit, «Pour lire Marie-Claire Blais», I'Action, vol. $L X, n^{\circ} 17935$ (12 avril 1967), p. 4.

AUDET, Jules, «Une saison dans la vie d"Emmanuel, roman de Marie-Claire Blais", Incidences, n० 10 (août 1966). pp. 39-41.

AURY, Dominique, "Vive le Canada ", la Nouvelle Revue française, vol. XIV, n' 168 (1er décembre 1966), pp. $1066-1070$.

BALDICK, Robert, «Recent Fiction. Getting on at all Costs", The Daily Telegraph (Londres), 13 avril 1967 (non vidi).

BARBEAU, Victor, "Marie-Claire Blais, la face et l'envers», Cahiers de I"Académie canadienne-francaise. 1966 , p. 48.

BARBERIS, Robert, "De l'exil au royaume", Maintenant, $n^{\circ} 64$ (avril 1967), pp. $122-124$.

- "Littérature québécoise et religionn, Maintenant, $\mathrm{n}^{\circ} 74$ (février-mars 1968. pp. 57-60 [reproduit dans la Fin du mépris. Montréal, Parti pris, 1978. pp. 154-174].

BARDE, Jacqueline. "Lus et élus à l'unanimitén, Elle. n० 1069 (16 juin 1966), pp. $130-132$. 
BARJON, Louis, "Prix littéraires. Une saison dans la vie d'Emmanue/", Études, $n^{\circ} 326$ (février 1967), pp. 210-222.

BASILE, Jean, "Une Canadienne publiée à Paris, a New York, etc.", le Devoir. vol. LVII, n०75 (31 mars 1966), p. 14.

- "Marle-Claire Blais, vous êtes née dans une ile... (entrevue)' ", le Devoir. vol. LVII, $n^{\circ} 94$ (23 avril 1966). p. 13.

—. «Pour Jacques Hébert, éditeur de Marie-Claire Blars: 'Quand je l'ai publiée. je ne croyais pas au succès' $"$, le Devoir, vol. LVII, $n^{\circ} 277$ (29 novembre 1966). p. 8.

-_._Après l'attribution du Médicis a Marie-Claire Blais. Autopsie d'un prix», le Devoir, vol. LVII, n² 281 (3 décembre 1966), pp. 13, 15.

- . Un entretien-vérité avec Marie-Claire Blais*, Québec 69, vol. V1, n 15 (février 1969), pp. 87-90.

BEAULIEU, Victor-Lévy, Jack Kerouac. Essai poulet, Montréal, les Editions du Jour. 1972, pp. 141, 231.

- * *'essai. (Vincent) Nadeau sur M.-C. Blais ou l'insolence d'ètre vivant •. le Devoir, vol. LXV, n० 132 (8 juin 1974), p. 17 (sur le Noir et le Tendre).

BELLEMARE, Yvon, "Le temps et l'espace d'Une saison dans la vie d'Emmanuel". I'Enseignement, ler avril 1969, pp. 5-6.

BERGER. Yves, "Une flùte à ravir d'horreur w, le Devoir, vol. LVII, n० 94 (23 avril 1966), p. 13 (reproduit du Nouvel Observateur).

n० 6914 (5 avril 1967), p. IV.

_. "Zola au Canada», le Nouvel Observateur, n 77 (4-10 mai 1966), p. 31.

BERNARD. Michel, "Prochain Épisode ou l'autocritique d'une impuissance». Parti pris. vol. IV, no 3 (novembre-décembre 1966). pp. $78-87$ (voir pages 78-79).

BERTHIAUME, Christiane, a Une ou deux choses que Claude Weisz sait de MarieClaire Blais*, Dimanche-matin, vol. XX, n० 9111 mars 1973). p. 44 (à propos de l'adaptation cinématographique).

BERTHIER, Pierre, "Le prix Médicis: Une saison dans la vie d'Emmanuel», la Cité (Belgique), 4 et 5 février 1967, p. 13 (non vidi).

BESSETTE, Gérard, GESLIN. Lucien et PARENT. Charles, "Le roman de la dernière heure. Marie-Claire Blais», Histoire de la littérature canadienne-françise par les textes. Des origines à nos jours, Montréal, Centre éducatif et culturel, 1968. pp. 626-633.

B!ANCHI, Pietro, *Una voce autentica dal Canada», // Giorno-Milano. 18 décembre 1967 (non vidi).

BOSCO, Monique, "Enfin un style Marie-Claire Blais», le Magazine Maclean, vol. V. $n^{\circ} 10$ (octobre 1965), p. 70-71.

1967) "Blais contre Ducharme*, le Magazine Maclean, vol. VII, n० 2 (février 1967), p. 54.

BOSQUET. Alain, «L'étrange talent de Marie-Claire Blais. Une saison dans la vie d'Emmanuels, le Monde, vol. XXill, $n^{\circ} 6612$ (16 avril 1966), p. 12.

BOUCQUEY, Eliane, “Une saison dans la vie d'Emmanuel, prix Médicis», la Revue nouvelle, vol. XLV. n० 1 (15 janvier 1967), p. 85.

BRIE, Albert, «Les propos du timide - Littérature vivante», la Presse, vol. LXXXI, n० 245 (23 octobre 1965), p. 3.

BRODIN, Pierre, "Une saison dans la vie d'Emmanuel", France-Amérique, 12 janvier 1967. p. 7 (non vidi).

BROY, Etiennette, aLa parole est aux lecteurs. Critique d'Une saison dans la vie d'Emmanuels, l'Action, vol. LX, n० 17983 (7 juin 1967), p. 5.

BRÜLE, Claude, *Elle a tout vu-entendu-lu (Une saison dans la vie d'Emmanuel)», Elle, n० 1064 (12 mai 1966), pp. 92-93. 
BUCKEYE. Robert, "Nouveau Roman made Easy», Canadian Literature, $n^{\circ} 31$ (Winter 1967), pp. 67-69.

CABAU, Jacques, "Roman français. L'enfer de Marie-Claire Blais», I'Express. $n^{\circ} 776$ (2-8 mai 1966), p. 114.

CARONI, Italo, "Uma estaçao no Canadá», Estado de S. Paulo (Supplemento Culturall, vol. III, n० 146 (19 aoùt 1979), p. 10.

CHABOT, Denys, "Automne 66: rentrée littéraire", le Tremplin, vol. I, n० 3 118 octobre 1966). p. 6.

CHALVIN, Solange, "Marie-Claire Blais, deuxième étoile féminine canadienne sur la scène littéraire parisienne», le Devoir, vol. LVII, n² 277 (29 novembre 1966). p. 9.

CHARENSOL, Georges, "Une saison dans la vie d'Emmanuel. le film de Claude Weisz”, les Nouvelles littéraires, $n^{\circ} 2473$ (17-23 février 1975), p. 15.

CHAUDHURY. Uta. Der frankokanadische Roman de la Terre. Eine Entwicklungstterdie. Frankfurt und München, Herbert Lang Ber, 1976, 229 pages (voir pages 177-191). (Europaische Hochscrulschreften, $n^{\circ} 38$ ).

CHESSEX, Jacques, "Marie-Claire Blais: Une saison dans la vie d'Emmanuel», la Nouvelle Revue française, vol. XIV, n' 168 (ler décembre 1968), pp. 1093 1094.

COCKE, Emmanuel, « Marie-Claire Blais: 'J'ai eu peur en lisant la version anglaise de mon livre: Une saison dans la vie d'Emmanuel'». Photo-journal. 25 décembre 1968. pp. 3-5 (non vidi).

COLIN-SIMARD. Annette. $\propto$ Soyez à la page. Le roman de la semaine. Saisissant*, le Journal du dimanche (Paris), 10 avril 1966. p. 8 (non vidi).

CREVIER, Gilles, «Le roman québécois à l'ère de la révolution tranquille *, l'Actua. lité, $\mathrm{n}^{\circ} 10$ (octobre 1967), pp. 51-52.

DAIGNEAULT. Claude, « Une saison dans la vie ... des mots au film (médiocre)», le Soleil, vol. LXXVII, n' 131 (9 juin 1973), p. 42.

DAVIES, Robertson, a Cold Comfort Farm. A Season in the Life of Emmanuels, New York Times Book Review, August 21, 1966, pp. 28-29.

DE GRANDPRE, Jacques,; aMarie-Claire Blais. Prix Médicis», le Monde protessionnel, vol. IV, $n^{\circ} 17$ (15 décembre 1966), pp. 6-7.

DELPECH, Jeannine, «Les enfants terribles du Québec», les Nouvelles littéraires, vol. XLVI, n² 042 (20 octobre 1966), p. 3.

- «Féroce et tendre. Marie-Claire Blais: le Médicis», les Nouvelles littéraires, vol. XLVI, n² 2048 (1er décembre 1966), p. 13.

DES CHAMPS, Grace, «Author of Price Winning Novel - 'Controversial' - Lives in Wellfleet «. Provincetown, Mass., May 19, 1966, p. 3 (non vidi).

DESROSIERS, Michèle, Marie-Claire Blais», la Terre de chez-nous, vol. XXXVIII, $n^{\circ} 41$ (4 janvier 1967). p. 18.

DONOGHUE, Denis, aA Season in the Life of Emmanue/.. New York Review of Books, June 9, 1966. p. 21.

DRAINIE, Bronwyn, aA Sesison in the Life of Emmanuel». The Canadian Reader, vol. VIII, $n^{\circ} 8$ (1968?). pp. 8-9.

DUBE, Gilles, "Une saison dans la vie d'Emmanuel - 1 - „, le Saint-Laurent, vol. LXXIV, $n^{\circ} 20$ (5 mars 1969), p. 22.

¿Une saison dans la vie d'Emmanuel-2 - $\rightarrow$, le Saint-Laurent, vol. LXXVI, $n^{\circ} 21$ (12 mars 1969), p. 20.

DUHAMEL, Roger, «Un livre raté et décevant... , Photo-journal, vol. XXX, n० 6125 mai 1966). p. 69.

, "Marie-Claire Blais», Manue/ de littérature canadienne-française, Montréal, les Éditions du renouveau pédagogique, 1967, pp. 138-139. 
. "Les romanciers canadiens à la unen, le Droit, vol. LIV, n 167 (5 novembre 1966), p. 12.

DUPIRE, Jacques, "Une saison ensoleillée dans la vie de Marie-Claire Blais". Échos-vedettes, vol. IV. n० 18 (21 mai 1966), p. 25.

DUSSAULT, Louis, «Marıe-Claire Blais. Une saison dans la vie d'Emmanuels, la Revue de l'École normale. vol. III, n 3 (février 1967), pp. 244-246.

ETHIER-BLAIS, Jean, a Le feuilleton littéraire. Une saison dans la vie d'Emmanual de Marie-Claire Blais v, le Devoir, vol. LVI, n० 159 (10 juillet 1965), p. 8 (reproduit dans Québec. vol. III (f́évrier 1966). pp. 119-121, et dans Signets II. Montréal, le Cercle du livre de France, 1967, pp. 228-232, sous le titre: * Entre femmes seules. Marie-Claire Blaiss).

- Les livres en français. Romans». University of Toronto Quarterly. vol. XXXV, n० 4 (July 1966), pp. 512-513.

EUVRARD, Michel, aUne tentative téméraire: sept films sur des écrivains québécoisn, Cinéma-Québec, vol. II, n 8 (mai-juin 1973), pp. 17-20 (reproduit dans Vient de paraître, vol. IX, n० 3 (septembre 1973), pp. 39.41).

FERRON, Jacques, \&Gabrielle Roy et Réjean Ducharme*, le Petit Journal, vol. XLIV. $n^{\circ} 2$ (2 novembre 1969), p. 71.

FICHE, J.L.Q., *Une saison dans la vie d'Emmanue/*, Vient de paraître, vol. IV, $n^{\circ} 6$ (décembre 1968), pp. 34-38 (non vidi).

FOURNIER. Roger. Le prix Médicis 1966, c'est un voyage chez les fantômes*, le Petit Journal, vol. XLI, n 8 (18 décembre 1966), p. 55.

FRANCION (pseudonyme), « Quand le roman d'ici devient international .. le Progres du Golfe, vol. LXII, $n^{\circ} 55$ (15 avril 1966), p. 19.

FRANCOEUR, Jacques, aMarie-Claire Blais fait parler d'elle dans Paris-Match*, Dimanche-matin. vol. XIII, n० 35 (18 septembre 1966). p. 40.

G., P., «Ex-Quebecer wins Award «, Quebec Chronicle-Telegraph, vol. CCIII, n 136 (November 29, 1966), p. 3.

-. "Psychological Study wins Top French Women's Award», Quebec Chronicle-Telegraph, vol. CCIII, n 136 (November 29, 1966), p. 6.

GALEY, Mathieu, *On rêve à tous les étages*, rexpress (Arts et loisirs), n 28 (6-12 avril 1966), p. 15.

- « Des vacances pour lire», /'Express, $n^{\circ} 38$ (10-16 avril 1967). p. 15.

GAUDET, Thérese, "Une saison dans le vie d'Emmanuel», le Devoir, vol. LVIII, n 69 (23 mars 1967), p. 4.

GAUGEARD, Jean, *Vive le Québecl», les Lettres françaises, $n^{\circ} 1159$ 11er-7 décembre 1966), pp. 3-4.

GAY, Paul, «e prix Médicis. Une saison dans la vie d'Emmanuel», le Droit. vol. LIV, $n^{\circ} 216$ (10 octobre 1966), p. 12.

GEOFFRION, Jacques, “Le Prix Médicis à une Québécoise», le Courrier de Berthier. vol. XXXIV, n' 11 (8 décembre 1966), p. 7.

GILLARD, Roger, «Marie-Claire Blais ou le roman retrouvé», le Thyrse, vol. LXIX, $n^{\circ} 2$ (mars-avril 1967), pp. 13-19.

GODARD. Barbara, «A Season in the Life of Emmanue/», Waves, 1977, p. 78 (non vidi).

GORIN, Jean-Pierre, «Médicis. Marie-Claire Blais», le Monde, vol. XX111, n 6805 (29 novembre 1966), p. 24.

GOURD, Anne, "Au pays des livres. Une saison en enfer». Actualite, vol. VII, $n^{\circ} 7$ (juillet 1966), p. 28.

GREFFARD, Madeleine, "Une saison dans la vie d'Emmanuel, katéidoscope de la réalité québécoise $*$, les Cahiers de Sainte-Marie, n 1 (mai 1966), pp. 17-22.

GRIVEL, Charles, «Prix littéraires... prix Médicis, Marie-Claire Blais, Une saison dans la vie d'Emmanuels, Het Franse Boek, vol. XXXVII, $n^{\circ} 1$ (janvier 1967), pp. 15-16. 
HAEDENS. Kléber, "Une romancière qui ne ressemble à personne ", le Nouveau Candide, 11-17 avril 1966, p. 26 (non vidi).

HAMELIN, Jean, « Une influence plus apparente que réelle», Liberté, \#42. vol. VII, $n^{\circ} 6$ (novembre-décembre 1966), pp. $471-474$.

HARGRAVES. Andrea. "A Season in the Life of Emmanuel", Quill and Quire, vol. XLII, $n^{\circ} 9$ (July 1976), p. 33.

HERTEL, Francois (pseudonyme de Rodolphe DUBE). "En marge d'un livre de Marie-Claire Blaıs. Une saison dans la vie d'Emmanue/s, I'Information médicale et paramédicale, vol. XIX, $n^{\circ} 2$ (6 décembre 1966), p. 32.

- ¿ Loisirs et culture $»$, I'Information médicale et paramédicale. vol. XIX, $n^{\circ} 4$ (3 janvier 1967), p. 24.

__. . Du misérabilisme intellectuel ... du besoin de se renier... et de quelques 'chefs-d'ceuvre'", I'Action nationale, vol. LVI, n' 8 (avril 1967), pp. 828-835.

HILL, Douglas, "A Truth of Childhood*. The Tribune, 8 juin 1967 (non vidi).

HILL, Harriet, aFacts \& Fancies», The Montreal Gazette, vol. CLXXXIX IMay 30, 1967), p. 17.

IBERT, Jean-Claude, "Succès féminin aux prix littéraires *, le Droit, vol. LIV, $\mathrm{n}^{\circ} \mathbf{2 5 0}$ (21 janvier 1967), p. 16.

L'ILLETTRE (pseudonyme de Harry BERNARD), aes lettres. L'indigeste navet de Marie-Claire Blais», le Bien public, vol. LVI, n० 11 (17 mars 1967), p. 6 (reproduit dans le Droit, vol. LIV, n 301 (22 mars 1967), p. 6).

IRWIN, Joan, \& French-Canadian Productivity», The Montreal Star (Entertainments), vol. XCVIII, n 305 (December 31, 1966), p. 5.

J., C., "L'enfer de Marie-Claire Blais», I'Express, $n^{\circ} 776$ (2-8 avril 1966), p. 114.

JASMIN, Claude, Rimbaud, mon beau salaud!. Montréal, les Editions du Jour, 1969, p. 38.

JAUBERT, Jacques, aPrix Femina: Nature morte devant la fenêtre. Prix Médicis: Une saison dans la vie d'Emmanuel (...) Une Québécoise à Paris *, le Figaro. vol. CXL, n० 6922 (29 novembre 1966), p. 21.

JOHNSON, Marigold, a New Fiction», The Times, n०56 902 (March 30, 1967), p. 6.

JUIN, Hubert, "Et le petit veau grand-maman m, les Lettres francaises, $n^{\circ} 1124$ (2430 mars 1966), pp. 6.7.

KANTERS, Robert, "Jeux d'enfants terribles", le figaro littéraire, no 1045128 avril 1966), p. 6.

KAPLAN, Bernard, French-Canadian Novelist and Paris Literary Jurors», The Montreal Star (Entertainments), vol. XCIX, $n^{\circ} 34$ (February 11, 1967), p. 4.

KATTAN, Naïm, «Lettre de Montréal*, Canadian Literature, $n^{\circ} 26$ (Autumn 1965), pp. 55-58.

- *Présence canadienne en France», Bulletin du Cercle juif, vol. XIII, n 117 (novembre 1966), p. 2.

- Lettre de Montréal ., Canadian Literature, $n^{\circ} 28$ (Spring 1966), pp. 52-55 (reproduit dans la Quinzaine litteraire, n० 7 (15 juin 1966), p. 10).

- Une saison dans la vie d'Emmanuels, Bulletin du Cercle juif, vol. Xll, $n^{\circ}$ 106 (octobre 1965), p. 3.

KRAFT, James, «Fiction as Autobiography. Notes on Pierre Vallières and MarieClaire Blais", Novel, vol. VI, n 1 (Fall 1972), pp. 73-78.

LABBE, Jean-Pierre, «arie-Claire Blais», Campus estrien (numéro spécial), avril 1968, pp. 10, 19.

LAPOINTE, Pierre, «Nos romans noirs», le Bien public, vol. LVI, $n^{\circ} 4127$ janvier 1967), p. 1.

LE CLEC'H, Guy, aPrix Médicis. Marie-Claire Blais: 'Je crains de devenir inhumaine' (entrevue)», le figaro litteraire, n 1076 (1er décembre 1966), p. 3. 
LĖGARE. Romain, "Les livres canadiens. Une saison dans la vie d'Emmanuel», Culture, vol. XXVII, n० 4 (décembre 1966), pp. 483-484.

LEEGER, Jules, * Commentaires sur la littérature canadienne-française», le Soleit. vol. LIX, n०284 (30 novembre 1966), p. 42.

LE ROUX, Claude, "Les Françaises marquent des points», Elle, n० 1097 (29 décembre 1966). pp. 25-35.

LEROUX, Normand, "Une saison dans la vie d'Emmanue/», Livres et Auteurs canadiens, 1965, pp. 51-52.

LEVESQUE. Robert. «Arts. Une saison dans la vie d'Emmanuel. "Mon intention $n$ 'était pas de faire un film québécois' '. Québec-Presse, vol. $V, n^{\circ} 10(11$ mars 1973), p. 23 (à propos de l'adaptation cinématographique).

L'HEUREUX, Gaston, „Profil de deux écrivains. Claire Martin et Marie-Claire Blais *. le Soleil. vol. LXIX, n० 170 (18 juillet 1966), p. 15.

LOBET, Marcel, aLe Canada renie Mario Chapdelaine», le Soir (Paris). 19 octobro 1967 (non vidi).

LOCKQUELL. Clément, "Horizons littéraires. Une saison dans la vie d'Emmanuel», le Soleil, vol. LVIII, $n^{\circ} 152$ (26 juin 1965), p. 14.

MACCABEE-IOBAL. Françoise, Sur-vivre et sous-vivre: la sexualité dans Une saison dans la vie d'Emmanuels, Coincidences, vol. IV, nos 2-3 (mai-décembre 1980). pp. 85-108.

MACNAMARA, Desmond, «Scape Goat*, New Statesman, vol. LXXII, n 1881 (March 31, 1967), p. 442.

MADOOCKS, Melvin, aFrom the Bookshelf. Remembering the Thaw", Christian Science Monitor, July 9, 1966, p. 9 (non vid).

MAILHOT, Luce, «Humanisme de Marie-Claire Blais », le Devoir, vol. LVIII, n 79 (5 avril 1967), p. 5.

MAJOR, André, «Arts. Lettres. Notre matriarcat *, le Petit Journal, vol. $X X X \mid X, n^{\circ} 39$ (25 juillet 1965), p. 30.

- "L'enfer de Green et de Blais», le Petit Journal, vol. XL, n 24 (10 avril 1966). p. 36.

- «Rina Lasnier et Marie-Claire Blais $\cdots$, le Petit Journal, vol. XL, n० 2818 mai 1966), p. 42.

- _ L'affaire Marie-Claire Blais *, Vient de paraître, vol. II. n 3 (mai 1966). pp. 17-18.

- «Au Sel de la semaine. Marie-Claire Blais vue par Reichenbach», le Devoir, vol. LVIII, $n^{\circ} 3(5$ janvier 1967), p. 8.

MAJOR, Jean-Louis, a Le roman depuis 1960 , Liberte, \#42, vol. VII, $n^{\circ} 6$ (novembredécembre 1965), pp. 461-463.

-. «Pour une lecture du roman québécois», Revue d'esthétique. vol. XXII. fascicule III (juillet-septembre 1969). pp. 251-261.

- «Marie-Claire Blais», Histoire de la littérature française du Québec, sous la direction de Pierre de Granspré, tome IV. Montréal, les Éditions Beauchemin. 1969, pp. 133-137.

MARCOTTE, Gilles, a Réflexions sur une année littéraire de qualitém, la Presse, vol. LXXXI, nº 6 (9 janvier 1965), p. 6.

- , Le roman canadien a la conquête de Paris», le Journal des Jeunesses musicales du Canada, décembre 1966. p. 10.

- a La dialectique de l'ancien et du moderne chez Marie-Claire Blais, Jacques Ferron et Réjean Ducharme», Voix et Images, vol. VI, n 1 (automne 1980). pp. $63-73$.

MAURIAC. Claude. "La vie des lettres. Une révélation du roman canadien-français», le Figaro, vol. CXL, n० 6718 (4 avril 1966), p. 13 (reproduit dans le Devoir, vol. LVII, no 84 (12 avril 1966), p. 10, sous le titre: "Le génie est là). 
MCDONNELL. Thomas, "Parables for our Timen. The Pilot, February 7, 1966. p. 15 (non vid).

MELCHIOR-BONNET, Christian, "Sorti des presses", A la page, $n^{\circ} 31$ (janvier 1967), p. 155.

MEAGEAL, Jean, “Une Canadienne dont on peut attendre beaucoup, Marie-Claire Blais", la Revue nationale (Belgique), $n^{\circ} 39$ (1967), p. 134 (non vidi).

MIGNON, Jean-Charles, "Romans du temps des monstres", le Soir (Bruxelles). n० 118 (19 mai 1966), p. 10.

MITTERAND, Henri, "Coup de pistolet dans un concert: Une saison dans la vie d'Emmanuel", Voix et Images, vol. II, $n^{\circ} 3$ (printemps 1977), pp. 407-417.

MORIN, Yvon, “Livres à lire au coin du feu. Une saison dans la vie d'Emmanuel:: l'Évangéline, vol. LXXX, n० 8494 (7 janvier 1967), p. 4.

MORVAN, J.-B., "Marie-Claire Blais. Une saison dans la vie d'Emmanuel(Grasset)», ttinéraires, $n^{\circ} 113$ (mai 1967). pp. 235-236.

MOSS, John, A Reader's Guide to the Canadian Novel, Toronto. McClelland and Stewart, 1981, 399 pages (voir pages 300-301).

MOWSHOWITZ, H.-B., "L'adolescent vaincu», Canadian Literature, $n^{\circ} 52$ (Spring 1972). pp. 48-56.

MUSETTE, L.A., "Une saison dans la vie d'Emmanuel de Marie-Claire Blais", I'Action, vol. LX, n० 17 (29 mars 1967). p. 4.

NADEAU. Vincent, Marie-Claire Blais: le noir et le tendre. Etude d'Une saison dans la vie d'Emmanuel suivie d'une bilbiographie critique, Montréal, les Presses de I'Université de Montréal, coll. Lignes québécoises, 1974, 109 pages.

“Comptes rendus. Philip Stratford Marie-Claire Blais», Etudes littéraires. vol. $V, n^{\circ} 1$ (avril 1972), pp. 152-154.

NEW YORK TIMES SERVICE, "Female Novelist Awarded French Literary Prize*, The Montreal Star, vol. XCVIII, n' 284 (December 6, 1966), p. 63.

NOURISSIER, François, "François Nourissier a lu cette semaine (..) Une saison dans la vie d'Emmanuel, roman de Marie-Claire Blais» les Nouvelles littéraires, vol. XLIV, n² 2048 (1er décembre 1966), p. 2.

OLLIER, Marie-Louise, "Notes de lecture. Une saison dans la vie d'Emmanue/", Études francaises, vol. II, $n^{\circ} 2$ (juin 1966), pp. 224-227.

O'NEIL, Jean, «L'univers hideux de Marie-Claire Blais», la Presse, vol. LXXXI, $n^{\circ} 151$ (3 juillet 1965), p. 5.

ONIMUS, Jean, «Les jeux de l'humour et du roman *, la Table ronde. $n^{\circ} 230$ (mars 1967), pp. $125-132$.

O'ROURKE, ÉLIZABETH, «Blais. Marie-Claire, A Season in the Life of Emmanuel», Best Sellers, vol. XXV (July 15, 1966). p. 144.

P.. D.S.. «Une saison dans la vie d'Emmanuel, par Marie-Claire Blais", le Peuple, 13 septembre 1966. p. 10 (non vidi).

P., N., «Marie-Claire Blais: Prix Médicis (Canadienne) écrit sa première ceuvre à vingt ans», France-soir, 29 novembre 1966, p. 2 (non vidi).

PELLETIER, Jacques, a Le Médicis à Marie-Claire Blais. Un prix mérité *. Je Soleil, vol. LXIX, n०287 (3 décembre 1966), p. 6.

PERRAULT, Luc, «Weisz: faire ou ne pas faire québécois (entrevue)», la Presse. vol. LXXX!X, $n^{\circ} 59$ (10 mars 1973), p. C- 11 (a propos de l'adaptation cinématographique).

PIA, Pascal, "Variété dans le roman», Carrefour. 16 mars 1966 (non vidi).

PILON, Jean-Guy, "Paris et le roman canadien*, le Devoir, vol. LVII, n 250 (27 octobre 1966), p. 12.

PILON, Michel, "Littérature. Une saison dans la vie d'Emmanuel de Marie-Claire Blais», Aujourd'hui Québec, vol. II, n 12 (février 1967), pp. 47-48. 
PILOTTE, Hélène, "Marie-Claıre Blais, prix Médicis 1966 ", Québec, vol. IV (février 1967), pp. 22-32.

POISSON, Roch, «Vie littéraire», Photo-journal, vol. XXX, $n^{\circ} 2$ (27 avril 1966), p. 77. p. 81 . "Mon histoire est simple...., Photo-journal, vol. XXX, n³ (4 mai 1966), p. . Un vaste marché à exploiter...*. Photo-journal, vol. XXX, n० 24 (28 septembre 1966), p. 64.

- $₫ 75000$ pour Une saison dans la vie d'Emmanuel», Photo-journal, vol. XXX, n० 33 (30 novembre 1966), p. 79.

PONTAUT, Alain, «Yves Berger: 'Cette explosion n'est-elle pas qu'un épiphénomène?" ${ }^{\prime}$, la Presse (supp.), vol. LXXXII, $\mathrm{n}^{\circ} 305$ (31 décembre 1966). pp. 7. 9.

PRIMEAU, Marguerite. - Lettre de France *, Canadian Literature, $n^{\circ} 36$ (Spring 1968), pp. 50-57.

RAMBURES, Jean-Louis, aLes meilleurs candidats pour les prix», Réalités, $n^{\circ} 249$ (octobre 1966). pp. 117.141.

RICARD, François, «Dans la collection 'Lignes québécoises"; une fable discutable sur Octobre 1970, le Jour (supp.), vol. I, n 46 (24 avril 1974), p. V-2.

RICAUMONT, Jacques de. « Romans français: Une saison dans la vie d'Emmanue/m, les Nouvelles litteraires, vol. XLIV, $n^{\circ} 2020$ (19 mai 1966), p. 5.

ROBERT, André, «Romans francais. Marie-Claire Blais: Une saison dans la vie d'Emmanue/», lo Quinzaine littéraire, n० 4 (1er mai 1966), p. 4.

ROBIDOUX, Réjean, LLautonomie d'une petite littérature», Mosaic, vol. $1, n^{\circ} 3$ (avril 1968), pp. 97.109.

ROBILLARD. Hyacinthe-M., Marie-Claire Blais ou le nécessaire bistouri», Maintenant, $n^{\circ} 54$ (juin 1966), pp. 211-213.

ROBIN, Etienne (pseudonyme de Hermas BASTIEN), a Le prix Médicis», I"Information médicale et paramédicale, vol. XIX, n 3 (20 septembre 1966), p. 22.

ROSBO. Patrick de, * Le froid de l'enfance *, les Lettres françaises, $n^{\circ} 1260$ (4 décembre 1968), p. 6 (reproduit dans le Devoir, vol. LIX nº 294 (14 décembre 1968), p. 14).

ROUSSAN, Jacques de, ane saison dens la vie d'Emmanue/., le Guide du lecteur canadien-français. Montréal. Agence de distribution populaire enregistrée. 1965. pp. 29-30.

—_. Une saison dans la vie d'Emmanue/w, la Patrie, vol. LXXXVI, n²6 (1er juillet 1965), p. 15.

ROUSSEAU, Louis, "Le roman. Un miroir de notre vécu religieux*, Communauté chrétienne, vol. VI, nº 36 (novembre-décembre 1967), pp. 456-467.

- Ie Symbole. Carrefour interdisciplinaire, Montréal, les Éditions de SainteMarie, 1969, tome 1, p. 50.

ROUSSEL, Romain, a Une saison dans la vie d'Emmanuel», le Monde et la Vie. novembre 1966 (non vidi).

ROY, Claire, «ll y a véritablement au Canada un phénomène Marie-Claire Blais le Nouvelliste, vol. XLV, $n^{\circ} 288$ (9 octobre 1965), p. 8.

ROYER, Jean, \& 1966: il y a loin de Laure Conan à Marie-Claire Blais», I'Action, vol. LIX, $n^{\circ} 17850$ (30 décembre 1966), p. 9.

SAINT-GermaIN. Pierre, ' 'Si je ne gagne pas ca va être drôle' - Marie-Claire Blais», la Presse. vol. LXXXIl, n० 276 (28 novembre 1966), pp. 1-2.

- «n grand événement dans la vie de Marie-Claire Blais „, la Presse (supp.). vol. $L X X X 11, n^{\circ} 281$ (3 décembre 1966), p. 12.

- "La littérature du Québec à l'Institut France-Canada», la Presse (supp.), vol. LXXXII, $n^{\circ} 293$ (17 décembre 1966)، p. 6 .

SAINT-ONGE, Paule, « Sur un fil, sur terre et dans les enfers $»$ Chätelaine, vol. VI, n० 9 (septembre 1965), p. 20. 
SCULLY, Robert-Guy, "Ce soir au Rivoli, Une saison dans la vie d'Emmanuel". le Devorr. vol. LXIV. n 57 (9 mars 1973), p. 14 (à propos de l'adaptation cinématographique).

SENART. Philippe, "Autour des romans. Les femmes et le mal», la Revue de Paris, vol. LXXXIII, $n^{\circ} 9$ (septembre 1966), pp. 124-130 (voir pages 126-127).

SHARP, Jean, "Responsible for Top New Storiesi, The Montreal Star, vol. XCVIII, $n^{\circ} 297$ (December 21, 1966), p. 10.

-. "Quebec-Born Marte-Claire Blais among Women News-Makersm, Quebec Chronicle-Telegraph, vol. CCIII, $n^{\circ} 160$ (December 28, 1966), p. 6.

SHEK, Ben-Zion, Social Realism in the French-Canadian Novel, Montreal, Harvest House, 1977, 326 pages (vorr pages 287-290).

SHEFFY, Pearl, "Women sweep Literature Prizes», The Gazette. vol. CLXXXIX (December 19, 1966), p. 35.

SIMARD, Jean, Nouveau Répertoire (essai), Montréal, les Éditions HMH, 1965, p. 23.

SIMON, Pierre-Henrı, «Actif et passif de l'année 1966», le Monde. vol. XXIII, $n^{\circ} 6830$ (28 décembre 1966), p. 10.

SLONIM, Marc, «European Notebook (...) French Canadians n, The New York Times Book Review. November 13, 1966, p. 56.

STRATFORD, Philip. aThe Voice of Spring in Montrealn, The Globe Magazine (supplément au Globe and Mail), vol. CXXIII, n³6337 (May 28, 1966), p. 17.

SYLVESTRE, Roger, a Un vent d'exotisme à Paris», Jeunesses littéraires du Canada francais, vol. IV, $n^{\circ} 2$ (février 1967), p. 5.

TADROS, Jean-Pierre, «De Weisz à Blais: 'Ce n'est qu'un souffle de liberté’, le Devoir, vol. LXIV, $n^{\circ} 58$ (10 mars 1973), p. 22 (à propos de l'adaptation cinématographique).

- —De Emmanuel à Sleuth. Du théâtre manqué et du film théâtral réussi ø, le Devoir, vol. LXIV, $n^{\circ} 64$ (17 mars 1973), p. 17 (a propos de l'adaptation cinématographique).

THÉORĖT, France. *Livres. Le monde étrange d'Emmanuel», Désormais. vol. I, $n^{\circ} 1$ (avril 1966), p. 14.

THERIAULT, Jacques, aPour Reichenbach, Marie-Claire Blais est un vrai tableau de Velasquez' *, le Devoir, vol. LVIII, n² (4 janvier 1967), p. 10.

_. «Marie-Claire Blais et le Médicis», Vient de paraître. vol. III, n० 1 (janvier 1967). p. 11.

TOUGAS, Gérard, *The Writing of the Decade. I. La littérature canadiennefrançaisen, Canadian Literature, n 41 (Summer 1969). pp. 104-110 (voir pages 108-110).

TRAIT, Jean-Claude, "L'étrange patience de M.-C. Blais», la Presse, vol. LXXXIX, $n^{\circ} 59$ (10 mars 1973), p. C-2 (à propos de l'adaptation cinématographique).

TREMBLAY, A., "Propos d'actualité. De Maria-Menaud a Emmanuel», le Soleil, vol. $L X X I, n^{\circ} 24$ (26 janvier 1968), p. 4.

TREMBLAY, Robert, «Une édition dans la vie d'Emmanuel», le Soleil, vol. LXXVIII, $n^{\circ} 78$ (30 mars 1974), p. 52 (sur l'édition de luxe).

VACHON, Georges-André, «L'espace politique et social dans le roman québécois», Recherches sociographiques, vol. VII, n 3 (septembre-décembre 1966), pp. 259-279.

VALIQUETTE, Bernard, *Une saison dans la vie d'Emmanue/*, Échos-vedettes, vol. III, $n^{\circ} 34$ (11 septembre 1965), p. 24.

_A la page. Une saison dans la vie d'Emmanuel», Echos-vedettes, vol. $V$. $n^{\circ} 16$ (6 mai 1967). p. 21.

VIATTE, Auguste, "Chronique des lettres françaises hors de France: le Canada", Conjonction, $n^{\circ} 105$ (octobre 1967), pp. 5-11. 
VISWANATHAN, Jacqueline, "Une saison dans la vie d'Emmanue/ de Marie-Claire Blais: introduction a l'analyse du personnage romanesquex. The french Review, vol. LII, $n^{\circ} 5$ (April 1979), pp. 755-758.

WALT, James, “Marie-Claire Blais. Une saison dans la vie d'Emmanue/», Books Abroad, vol. XLII (1968), p. 66 (non vidh).

WARDLE, Irving, «Putting Quebec on the Map», The Observer, $n^{\circ} 9168$ (April 2. 1967), p. 27.

WEEKS. Edward, a Rebellion in Canada . The Atlantic Monthly, $n^{\circ} 218$ (July 1966). p. 136.

WIEGHTMAN, John, aRinging out the New: Fiction in France». The Observer. n० 9159 (January 29, 1967), p. 27.

WOODCOCK. George, «A Season in the Life of Emmanue/*. Harper's Magazine, n० 233 (July 1966). p. 95 (reproduit dans Commonweal, October 7, 1966. pp. 28-30).

WORDSWORTH, Christopher, *Women of Athens», The Guardian, $n^{\circ} 37648$ (March 31, 1967), p. 11.

\section{Theses}

BISSONNETTE. Pierrette. "Une saison dans la vie d'Emmanuel, étude de l'espace», mémoire de maîtrise ès arts, Ottawa, Université d'Ottawa, 1977.

FORTIN, Pierre, * Le bestiaire de Marie-Claire Blais: une lecture d'Une saison dans la vie d'Emmanuel et des Manuscrits de Pauline Archange ", mémoire de maitrise ès arts, Montréal, McGill University, 1972.

HÉTU, Dolorès-Camille, L'engagement littéraire durant les années soixanten. mémoire de maîtrise ès arts, Edmonton, University of Albertz, 1978.

MORIN, Yvon, a Une saison dans la vie d'Emmanuel. Les structures de l'couvre et le style de Marie-Claire Blais x, thèse de doctorat en philosophie (Ph.D.), Montréal, Université de Montréal, 1972.

NADEAU, Vincent, «Le noir et le tendre: Une saison dans la vie d'Emmanue/m, thèse de diplôme d’études supérieures (D.E.S.), Montréal, Université de Montréal. 1967 (en appendice, le manuscrit d'Une saison dans la vie d'Emmanuen.

\section{L'Insoumise}

(Anonyme), Marie-Claire Blais: I'Insoumise», le Soir (Belgique) 10 mars 1971. p. 26 (non vidi).

(7 mai 1966), p. 16.

_._. "Marie-Claire Blais: I'Insoumise». la Libre Belgique. 19 mars 1971. p. 7 (non vidi).

-_. Marie-Claire Blais», le Soleil, vol. LXXIC, n 86 (8 avril 1971), p. 61.

*On réédite à Paris deux romans de Marie-Claire Blais*, le Droit, vol. LIX, $n^{\circ} 12$ (10 avril 1971), p. 31 .

BELLEFEUILLE, André, «L'Insoumise, un roman de Mario-Claire Blais", les Cahiers de Cap-Rouge, vol. IV, $n^{\circ} 1$ (1976), pp. 59-74.

BERCOFF, André, a Le désespoir par deux*, l'Express, n० 1033 (26 avril-2 mai 1971). p. 13 .

BERGER, Yves, «Le néant et l'infini : les nouveaux livres: le Jour est noir et l'Insoumise», le Figaro littéraire, $n^{\circ} 1291$ (15-21 février 1971), p. 20.

80SCO. Monique, \& Les arts et les autres. Au lieu de poursuivre un certain succès.... le Magazine Maclean, vol. VI, nº (août 1966), p. 43.

BOSQUET, Alain, «Entre psychologie et psychanalyse. Les révoltes de Marie-Claire Blais», le Monde, vol. XXVIII, n 8155 (2 avril 1971), p. 18. 
BOURQUE, Paul-André, "Marie-Claire Blais. Le Jour est noir suivi de I'Insoumise", Livres et Auteurs québécois, 1979, pp. 26-27

CLOUTIER, Cécile, "L'Insoumise de Marie-Claire Blais", Livres et Auteurs canadiens, 1966. pp. 29-31.

DAVIES, Gillian, "The Fugitive». The Fiddlehead, n० 121 (Spring 1979), pp. 163-164.

GAUGEARD, Jean, "Tendresses funèbres ", Lettres françaises, $n^{\circ} 1381$ (14-20 avril 1971 . p. 3.

GODIN, Gérald, “Les arts et les autres. Marie-Claire Blais parle d Gérald Godin. 'Suis à la mer... Écris beaucoup... très heureuse' ", le Magazine Maclean. vol. VI, n 5 (mai 1966), p. 71.

HARDY, Jean, "Les livres. Marie-Claire Blais. L'insoumise", Relations, $n^{\circ} 325$ (mars 1968), p. 95.

HOULE, Benoit, "Un troisième livre de Marie-Claire Blais publié chez Grasset", le Soleil, vol. LXXIV, $n^{\circ} 77$ (29 mars 1971), p. 14.

HUOT, Maurice, *De Christine de Pisan à Marie-Claire Blais», le Droit, vol. LIV, $n^{\circ} 105$ (30 juillet 1966), p. 12.

IRWIN, Joan, "Pessimistic Marie-Claire Blaisn, The Montreal Star (Entertainments), vol. CXVIII, n 149 (June 25, 1966), p. 6.

LANDRY, Francine, "Marie-Claire Blais*, Points d'interrogation, 25 février 1967. (non vidn).

LAVIGNE, Nicole, "L'Insoumisen, la Revue de Terrebonne, vol. VIII, n० 7 18 juillet 1966), p. 13.

LEGARE, Romain, "Les livres canadiens. L'Insoumise, roman", Culture, vol. XXVII, $n^{\circ} 4$ (décembre 1966), pp. 483-484.

LOCKOUELL, Clément, aL'Insoumise, roman de Marie-Claire Blais", le Soleil, vol. LXIX, no 111 (7 mai 1966), p. 32.

MAJOR, André, «Rina Lasnier et Marie-Claire Blais», le Petit Journal, vol. XL, $n^{\circ} 28$ (8 mai 1966), p. 42.

MARCOTTE, Gilles, "Les livres. Marie-Claire Blais après Emmanuel...», la Presse (supp.), vol. LXXXII, n 106 (7 mai 1966), p. 4 (reproduit dans Québec. vol. III (octobre 1966), pp. 79-81.

PETIT, Jacques, «Romanciers contemporains. Marie-Claire Blais. L'Insoumisen, le Français dans le monde, vol. XI, $n^{\circ} 84$ (octobre-novembre 1971), pp. 45-46.

PILOTE, Hélène, a Marie-Claire Blais, l'Insoumise des lettres canadiennes *. Châtelaine, vol. VII, n० 8 (août 1966), pp. 21-23, $51-54$.

ROY, Claire, «Une mélodie poétique à trois voix. L'/nsoumise de Marie-Claire Blais ", le Nouvelliste, vol. XLVI, n 170 (21 mai 1966), p. 16.

SAINT-ONGE, Paule, "Châtelaine a lu pour vous. Au menu: une romancière. un humoriste et un chansonnier ‘, Chátelaine, vol. VII, $n^{\circ} 7$ (juillet 1966). p. 18.

TAAFFEE. Gerald, a How a Girl from Quebec Woved North America's most Distinquished Literary Critic - then Laid and Eggn. The Montreal Gazette (Magazine), vol. CLXXXIX (July 9. 1966), p. 21.

VALIQUETTE. Bernard, “A la page. L'Insoumise, roman de Marie-Claire Blais", Échos-vedettes, vol. IV, $n^{\circ} 27$ (23 juillet 1966), p. 24.

WOLFROM, J.-D., "L'inquiétude et la passion hantent le troisième (sic) livre de Marie-Claire Blais». France-Soir, 20 mars 1971, p. 11 (non vidi).

\section{David Sterne}

(Anonyme), "Blais (Marie-Claire). David Sterne», Fiches bibliographiques de litterature canadienne, $n^{\circ} 234$ (septembre 1967).

- ¿David Sterne de Marie-Claire Blais», Escho-griffe, vol. XII, $n^{\circ} 2$ (novembre 1967). p. 5. 
- aLes livres en bref. David Sterne», le Québec en bref, vol. I, $n^{\circ} 10$ (novembre 1967), p. 22.

—. "David Sterne de Marie-Claire Blais», Québec, vol. V (février 1968), pp. 96-98.

BEAUDRY-GOURD, Anne, "ll connaît nos défauts et nos tares», la Frontière, vol. $X X X, n^{\circ} 19$ (8 novembre 1967), p. 29.

- LLe roman de la mort et du refus de vivren, la frontière. vol. XXX, n० 23 (6 décembre 1967), p. 29.

BEAUREGARD, Hermine. "J'ai appris par-dessus la corde à linge...*, le Petit Journal, vol. XLI, n' 45 (3 septembre 1967), p. 46.

BELLEFEUILLE, André, \& Un roman de Marie-Claire Blais: David Sterne», les Cahiers de Cap-Rouge, vol. III, n' 3 (1975), pp. 59-61.

BERNIER, Conrad, «L'offensive de nos romanciers (...) David Sterne, de MarieClaire Blais: un mauvais roman, détestable, qu'on n'aurait pas dủ publier», le Petit Journal, vol. XLI, no 48 (24 septembre 1967), p. 58.

BONNEVILLE. Jean-Pierre, "L'indigeste navet de Marie-Claire Blais", la Frontière. vol. XXIX, n० $40(5$ avril 1967$)$, p. 7.

BOSCO. Monique. aLes lettres. Un voyage poétique aux enfers*, le Magazine Maclean, vol. VIII, n० 1 (janvier 1968), Dp. 46-47.

BOULERICE, Jacques, ¿David Sterne, le goùt du fiel», le Richelieu, vol. XXXIII, n० 42 (septembre 1967), p. 36.

CAVANAGH, David, "The Darkness at the Centre: David Sternen, Journal of Canadian Fiction, vol. III, n०3 (1974), pp. 105-106.

CHARBONNEAU, Pierre, :David Sterne : succès et échec de la conscience? $*$ Lettres et Écritures, vol. V. $n^{\circ} 2$ (décembre 1967), pp. 5-9.

CHARLAND. Jean-Paul, “Chronique littéraire. David Sterne ", le Médecin du Québec, vol. III, $n^{\circ} 3$ (mars 1968), pp. 54-55.

DROLET, Simon, «David Sterne de Marie-Claire Blais», Livres et Auteurs canediens, 1967, p. 43.

DUGUAY, Raoul, a Littérature québécoise. David Sterne: le pathétique de la misère ou la gloire de la finitude , Parti pris, vol. V. $n^{\circ} 1$ (septembre 1967). pp. 46-49.

ÉTHIER-BLAIS, Jean, «David Sterne de Marie-Claire Blais. Monstres et transcendance*, le Devoir, vol. LVIII, n० 203 (2 septembre 1967), p. 13 (reproduit dans Québec, vol. V (février 1968), pp. 96-98).

FECTEAU, Hélène, a Notes de lecture. David Sterne, roman par Marie-Claire Blais», Liberté, \#55, vol. $X, n^{\circ} 1$ (janvier-février 1968), pp. 68-69.

GAY, Paul, *David Sterne*, le Droit, vol. LV, n 146 (16 septembre 1967), p. 10.

HENAIRE, Jean, «David Sterne de Marie-Claire Blais. Trilogie du désespoir , le Carabin, vol. XXVIII, nos 5-6 (10 et 12 octobre 1967), p. 6.

HERTEL, François (pseudonyme de Rodolphe DUBÉ), Un autre livre faible». I'Information médicale et paramédicale, vol. XX, $\mathrm{n}^{\circ} 2$ (5 décembre 1967), p. 23.

IRWIN, Joan, *The Poetry of Despair*, The Montreal Star, vol. XCIX, n० 229 (September 30, 1967). p. 8.

LABBE, Jean-Pierre, "Marı-Claire Blais", Campus estrien (numéro spécial a Arts et lettres au Québec $\gg$ ), avril 1968, p. 19.

LANGLOIS, Conrad, «Marie-Claire Blais et son univers étrange», la Patrie, vol. LXXXVIII, $n^{\circ} 36$ (10 septembre 1967), p. 56.

LAVIGNE, Nicole, "A travers les livres", la Revue de Terrebonne, vol. IX, $n^{\circ} 10$ (21 septembre 1967), p. 44.

LEVY. Bernard, aLivres. Réalité psychologiquen, Sept-Jours, vol. II, $n^{\circ} 3$ (1er-7 octobre 1967), p. 44.

LOCKQUELL, Clément, «Le dernier roman de Marıe-Claire Blais, David Sterne», le Soleil, vol. LXX, no 215 (9 septembre 1967), p. 26. 
LOMBARD. Bertrand. (pseudonyme d'Émile BÉGIN). "Au long d'une vie», I'Action, vol. LX, no 18049 (25 août 1967), p. 17.

MAJOR. André, "A bord du Flandre. Marie-Claire Blais lance David Sternen. le Devoir, vol. LVIII. n² 200 (30 août 1967). p. 3.

__. "Grandeur et misère de la jeunesse", le Devorr. vol. LVIII, n 301 (30 décembre 1967). p. 14.

MARIETTE (pseudonyme), "Le plus croyant", Sept-Jours, vol, I, n²0 (28 janvier 1967), p. 5.

MARSHALL, Joyce, *Three from the Other Nation», The Tamarack Review, $n^{\circ} 46$ (Winter 1968), pp. 112-113.

MORIN, Yvan, "Lectures d'été. Le pläisir de souffrir. David Sterne", I'Évangéline. vol. LXXX, n8 8716 (30 septembre 1967), p. 4.

MORISSETTE. Brigitte, "Marie-Claire Blais, un exil fécond", la Patrie, vol. LXXXVIII, $n^{\circ} 3$ (15 janvier 1967), p. 75.

- Une nouvelle saison dans la vie de Marie-Claire Blais», la Patrie, vol. LXXXVIII, n० 31 (6 août 1967), p. 51.

PARÉ, Paul, aDavid Sterne de Marie-Claire Blais. Le meilleur dans le pire des mondes». l'Enselgnement, vol. XXI, $n^{\circ} 2$ (15 septembre 1967), p. 14.

PIAZZA. François, "La saison littéraire $1967-1968$ a pris son départ en grand», Échos-vedettes, vol. V. no 34 (9 septembre 1967), p. 7.

POISSON, Roch, "Le deuxième roman de la saison: David Sterne de Marie-Claire Blais», Photo-journal, vol. XXXI, n²0 (30 août 1967). p. 73.

- Le premier lancement de la saison: Marie-Claire Blais». Photo-journal, vol. XXXI, n० 21 (6-13 septembre 1967), p. 63.

- , Quatre nouveaux livres. Les Québécois: Louis Préfontaine, David Sterne et les autres $*$, Photo-journal, vol. XXXI, $n^{\circ} 24$ (27 septembre-4 octobre 1967). p. 64.

PONTAUT, Alain, "L'exiguïté de ce jardin rongé par les flammes», la Presse, vol. LXXXIII, n $204(2$ septembre 1967), p. 25.

ROBERT, Guy, « Canada français: une curieuse aventure. Le roman et le théátre . la Gazette littéraire, vol. CLXVI, no 204 (31 août-1er septembre 1967), p. 14.

ROBIN, Etienne (pseudonyme de Hermas BASTIEN). *David Sterne*, IInformation médicale et paramédicale, vol. XX, n० 5 (16 janvier 1968), p. 26.

RUDZIK, O.H.T., «David Sterne*, University of Toronto Quarterly, vol. XLIII, n० 4 (Summer 1974), p. 343.

SAINT-ONGE, Paule, "Les mondes de Blais, Basile et Sarrazin". Châtelaine, vol. VIII, $n^{\circ} 11$ (novembre 1967), p. 18.

SMITH, Beverly, «Selves Condemned. David Sterne: Marie-Claire Blais», Books in Canada, vol. II, $n^{\circ} 4$ (October 1973), pp. 13-14.

T(HÉBERGE). J(ean)-Y(ves). «David Sterne ou la souffrance», le Canada francais, vol. CVIII. $n^{\circ} 18$ (28 septembre 1967), p. 26.

VALIQUETTE, Bernard, «A la page. David Sterne», Échos-vedettes, vol. V. $n^{\circ} 38$ (7 octobre 1967), p. 23.

\section{Les Manuscrits de Pauline Archange, Vivre! Vivre! et les Apparences}

(Anonyme), \& Le livre qu'il faut lire cette semaine: Manuscrits de Pauline Archange par Marie-Claire Blais», Elle, n० 1192 (21 octobre 1968), pp. 174-186.

- *Manuscrits de Pauline Archange», I'Écho du Bas-Saint-Laurent, vol. XXXV, n० 36 (30 octobre 1968). p. 29.

- Blais (Marie-Claire). Manuscrits de Pauline Archange , Fiches bibliographiques de littérature canadienne. n० 532 (décembre 1968). 
- -Aquin, Blaıs et Dumont reçoivent le prix du Gouverneur général», te Droit. vol. LVII, $n^{\circ} 22$ (22 avril 1969). p. 12.

- Hubert Aquin, Marie-Claire Blais et Fernand Dumont, lauréats des Prix du Gouverneur Général „, la Presse, vol. LXXXV, n० 98 (22 avril 1969), p. 22.

- "The Literary Prize for Woman Writer . The Quebec Chronicle-Telegraph. vol. CCV, $n^{\circ} 254$ (April 22, 1969), p. 2.

- a Les Prix du Gouverneur général. Lauréats québécois: Dumont, MarieClaire Blais et Aquin», le Devoir, vol. LX, n० 93 (22 avril 1969), p. 10.

- "Vivre! Vivre! (malgré tout) de Marie-Claire Blais», Sept-Jours. vol. IV. $n^{\circ}$ i 2 (6 décembre 1969), p. 34.

- . Vivre! Vivre!" . le Livre canadien, vol. I, n० 15 (1970).

-. -Les Apparences., le Livre canadien, vol. I, n 146 (1970).

___ alivres canadiens récents. Vivre! Vivrelı, l'Église canadienne, vol. III, $n^{\circ} i$ (janvier 1970), p. 28.

- Les livres. Les Apparences par Marie-Claire Blais-, Bulletin du Cercle juif, vol. XVI, n' 149 (novembre 1970), p. 5.

- Les Apparences», lÉglise canadienne, vol. III, n 10 (novembre 1970), Pp. 347-348.

AMETTE, Jean-Pierre, «Romans français ", la Nouvelle Revue francaise, voi. XXXIII. $n^{\circ} 193$ (1er janvier 1969), pp. 141-142.

BARRETTE. Roland, \& Lectures. La saison littéraire s'annonce fructueuse „, Dimanche-matin, vol. XVIII, $n^{\circ} 35$ (6 septembre 1970), p. 82.

BASILE, Jean, «Livres/déclarations de Marie-Claire Archange. Un entretien-vérité avec Marie-Claire Blais», le Devoir, vol. LIX, n 245 (19 octobre 1968), p. 11 (reproduit dans Québec, vol. VI (février 1969), pp. 87-90).

BEAULIEU, Ivanhó, «DeuX couvres totalement différentes $»$, le Soleil, vol. LXXXVI, $n^{\circ} 227$ (26 septembre 1970), p. 50.

BEAULIEU, Michel, aLivres d'ici. Du bizarre au fantastique *, Digeste éclair, vol. V. $\mathrm{n}^{\circ} 12$ (décembre 1968), pp. 21-22.

BEAULIEU, Victor-Lévy, Une littérature en vacances", Échos-vedettes, vol. VII, $n^{\circ} 26$ (12 juillet 1969), p. 26.

- Littérature québécoise. L'année d'une prise de conscience collective. Marie-Claire Blais et Réjean Ducharmex, Maintenant, n 91 (décembre 1966). pp. $312-313$.

BEAVER, John, «Dürer's Ange/*, Quill and Quire, vol. XLIII, n' 3 (February 15, 1977), p. 8.

BERCOFF, André, "L'Astragale au Canada", l'Express, n० 913 (5 janvier 1969), p. 67.

BERTHIAUME. André, *Chroniques. Le roman * Études francaises, vol. VI, n० 4 (novembre 1970), pp. 490-503 (voir pages 495-497).

BOILEAU, Monique, "Le livre du mois. Blais, Marie-Claire, les Apparences., Fevillets des Jeunesses littéraires du Québec. vol. III, nos 15.16 (août-septembre 1970), p. 6.

BONNEFOY. Claude, "Une romancière a Sodome „, les Nouvelles littéraires, n० 14 (1973) (non vidi).

BOSCO. Monique, a Les arts et les autres. Grâce à Blais et Ducharme. 1968 fut une grande année», le Magazine Maclean. vol. IX, n 1 (janvier 1969), p. 46.

BOSQUET, Alain, «Trois romancières», le Combat, n० 7569 (14 novembre 1968), p. 8.

CHARLAND, Jean-Paul, *Chronique littéraire. Les Apparences*, le Médecin du Québec, vol. VI, n० 1 (janvier 1971). p. 73.

CHÁTILLON. Pierre, "Comptes rendus. Marie-Claire Blais. Manuscrits de Pauline Archange", Études françaises, vol. V. $n^{\circ} 1$ (février 1969). pp. 98-100. 
CLOUTIER, Cécile. aes Apparences de Marie-Claire Blaıs ", Livres et Auteurs québécois. 1970. pp. 60-61.

DAVIES. Gillian. -Durer's Angel", The Fiddlehead. no 114 (Summer 1977). pp. 147.149

DUHAMEL. Roger. r Hors des voies traditionnelles. Roman», le Droit, vol. LVI, $n^{\circ} 214$ (7 décembre 1968), p. 7.

_- "Manuscrits de Pauline Archange de Marie-Claıre Blais ". Livres et Auteurs canadiens. 1968. pp. 41-42.

- De quelques publications récentes», le Droit, vol. LVIII, $n^{\circ} 282$ (27 février 19711 , p. 7.

ETHIER-BLAIS, Jean, a Manuscrits de Pauline Archange. Un manuscrit qui eût dû rester dans le tIroir ", le Devoir, vol. LIX, n' 282 (30 novembre 1968), p. 16.

_- Vivre! Vivre! de Marie-Claire Blais. Le jardin de Pauline Archange débroussaillé. . le Devoir, vol. LX, n² 278 (29 novembre 1969). p. 13 (reproduit dans Québec, vol. VII (mars 1970). pp. 107-110).

—_. - Les Apparences de Marie-Claire Blais: une entrée dans la vie», le Devoir. vol. LXI, nं 230 (3 octobre 1970). p. 14.

_. a Un Noèl de lecture ». le Devoir. vol. LXI, $n^{\circ} 289$ (12 décembre 1970), p. 24.

FABI, Thèrèse, a $L a$ ville dans trois romans de Marie-Claire Blais "I"Action nationale. vol. LXII, $n^{2} 9$ (juin 1973), pp. 829-843.

FERAON. Jacques, aLes arts et les autres. Les belles-lettres putassières", le Magazine Maclean. vol. X, n' 12 (décembre 1970). p. 50.

GAY, Paul, „Pauline Archange; Manuscrits - Vivre! Vivre!॰, le Droit, vol. LVII, n' 235 (3 janvier 1970), p. 7.

GODARD. Barbara, aLes Apparences ", Waves. 1977, p. 77 (non vidi).

GUAY, Jean-Pierre. aLes Manuscrits de Pauline Archange*, IAction, vol. LXII, n' 18770 (9 mai 1969), p. 17.

KERCHOVE, Arnold de, "Manuscrits de Pauline Archange... enfants terribles", Revue générale belge, $\mathrm{n}^{\circ} 104$ (10 décembre 1968), pp. 108-111.

LANTHIER. Daniel, \&Étude de quelques coordonnées spatio-temporelles ou les Apparences sont souvent trompeuses.. Études de la littérature québécoise sous la direction de Joseph BONENFANT. Sherbrooke, 1971. pp. 87-104.

LAURENCE. Margaret, «Dürer's Ange/*, Books in Canada, vol. VI, n 4 (April 1977). pp. 25-26.

LEDUC. Paule, - Le roman *, Études littéraires, vol. II, n 2 (août 1969), pp. 205-210.

LEPAGE. Yvan-G., «Vivre! Vivre! de Marie-Claire Blais», Livres et Auteurs québécois, 1969, pp. 24-25.

LÉVY, Bernard, × Des phrases longues et belles», Sept-jours, vol. II, n० $28(24-30$ mars 1968). p. 48.

MAJOR. André. a Francfort 1969, un roman de M.-C. Blais, les colères de Pierre Vadeboncceur et une suite de petits riens *, le Devoir, vol. LX, n०260 18 novembre 1969l, p. 14.

MALENFANT, Valois, «Du gris au noir ", le Lien (Ecole normale Laval), 6 mars 1969. p. 3.

MARCHAND, Alain-Bernard. aLes Manuscrits de Pauline Archange: Éros et Thanatos =, Voix et Images, vol. VII. $n^{\circ} 2$ (hiver 1982), pp. 343-349.

MARTEL, Réginald, a Le retour de Pauline Archange. Vivre! Vivre!s, la Presse, vol. LXXXV. $n^{\circ} 260$ (15 novembre 1969), p. 28.

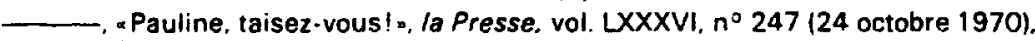
p. C-3

MCPHERSON, Hugo, "Blais, Godbout, Roy, Love Art Time". The Tamarack Review. $n^{\circ} 57$ (Summer 1971), pp. 84-88. 
MORIN, Yvon, "Lecture d'automne. Manuscrits de Pauline Archange *, l'Évangéline. vol. LXXXI, n० 9057 (2 novembre 1968), p. 4.

NOURISSIER, FrançoIs, «François Nourissier a lu cette semaine: Manuscrits de Pauline Archange, roman de Marie-Claire Blais», les Nouvelles littéraires, vol. XLVI, n०2151 (12 décembre 1968), p. 2.

O'NEIL-KARCH, Mariel, = Durer's Ange/», The Canadian Forum, vol. LVII, n' 672 (June-July 1977), p. 58.

P., P., «Marie-Claire Blais et Jean d'Ormesson ou les extrêmes», Libre Belgique, 8 novembre 1968, p. 8 (non vidi).

POISSON, Roch, «Des Québécois pour la rentrée: Blais, Ducharme, Félix Leclerc», Photo-journal, vol. XXXII, n० 22 (11-18 septembre 1968), p. 50.

- Qui a peur de Marie-Claire Blais?*, Photo-journal, vol. XXXI, n 52 (10-17 avril 1968), p. 59.

- aLes enfants tuberculeux de Mlle Blais», Photo-journal, vol. XXXII, n० 29 (6 novembre 1969), p. 51.

PONTAUT, Alain, «Marie-Claire Blais ou l'obsession des monstres. Manuscrits de Pauline Archange», la Presse, vol. LXXXIV, n 244 (19 octobre 1968), p. 25.

POULIN, Gabrielle, «Marie-Claire Blais: les Apparences», Relations, n 360 (mai 1971), p. 153.

PRESSE CANADIENNE, Marie-Claire Blais, Hubert Aquin et Fernand Dumont, lauréats des prix du Gouverneur général ». la Tribune, vol. LX. n 53 (22 avril 1969), p. 7.

_. «ix écrivains canadiens seront honorés a Ottawa , la Voix de l'Est, vol. XXXIII, n 201 (22 avril 1969), p. 2.

— - Les lauréats des prix du Gouverneur général $\nsim$, le Nouvelliste, vol. XLIX, n० 147 (24 avril 1969), p. 15.

ROBIDOUX, Réjean, \&Livres en français. Romans, nouvelles et contes $»$ University of Toronto Quarterly, vol. XXXVili, n 4 (July 1969), pp. 471-472.

- Livres en français. Romans, récits, nouvelles, contes\%, University of Toronto Quarterly, vol. XXX|X, n० 4 (July 1970), p. 437.

ROLIN, Gabrielle, Les maléfices dune enfance. Les Manuscrits de Pauline Archange de Marie-Claire Blais», le Monde (des livres), vol. XXV, $n^{\circ} 7428$ (30 novembre 1968), p. I.

ROSBO, Patrick de, a Le froid de l'enfance *, les Lettres francaises, n 1260 (4 décembre 1968), p. 6 (reproduit dans le Devoir, vol. LIX, n² 294 (14 décembre 1968), p. 14).

ROUX, Paul, «Manuscrits de Pauline Archange. Un long constat d'impuissance», le Soleil, vol. LXXI, n 266 (9 novembre 1968), p. 38.

_. "L'enthousiasme aurait-il disparu? *, le Soleil, vol. LXXII, n 268 (15 novembre 1969), p. 52.

ROYER, Jean, «Le monde de Marie-Claire Blais», I'Action, vol. LXII, n 18929 (15 novembre 1969), p. 19.

- "Pauline Archange et les Apparences", I'Action, vol. LXII, n० 19198 (3 octobre 1970), p. 17.

SAINT-ONGE, Paule, «Trois romans à s'offrir en cadeau *, Châtelaine, vol. IX, $n^{\circ} 12$ (décembre 1968), p. 10.

- «Contre les limites fictives de la réalité», Chátelaine, vol. XI, $n^{\circ} 2$ (février 1970). p. 14.

- "Petour de trois grands écrivains féminins", Châtelaine, vol. $\mathrm{XI}, \mathrm{n}^{\circ} 12$ (décembre 1970). p. 10.

SENART, Philippe, «Marie-Claire Blais. Manuscrits de Pauline Archange», la Revue de Paris, n 76 (janvier 1969), pp. 120-121. 
T(HĖBERGE). J(ean)-Y(ves). "Un autre grand roman de M.-C. Blais. Manuscrits de Pauline Archange ", le Canada francais, vol. $\mathrm{ClX}, \mathrm{n}^{\circ} 26$ (21 novembre 1968), p. 26.

- "Vivre! Vivre!", le Canada francais. vol. CX. $n^{\circ} 38$ (11 février 1970), p. 24.

TREMBLAY, Denis, “Les Apparences», Montréal-matin, vol. XLI, nं० 59111 septembre 1970), p. 16.

- «Cinq livres. Les Apparences», Montréal-matin, vol. XLI, n० 7915 octobre 1970), p. 14.

TURCOT, Lionel. aManuscrits de Pauline Archange par Marie-Claire Blais., les Jeunesses fittéraires du Québec, vol. VI, n 1 (septembre-octobre 1968), p. 15.

Thèse

FORTIN, Pierre, aLe bestiaire de Marie-Claire Blais: une lecture d'Une saison dans la vie d'Emmanuel et des Manuserits de Pauline Archange», mémoire de maitrise ès arts, Montréal, McGill University, 1972.

\section{Le loup}

(Anonyme), «Le Loups, le Livre canadien, vol. III, n 132 (1972).

- a de magazine français le Point. Avec le Loup. Marie-Claire Blais est devenue 'un authentique écrivain' ", le Devoir, vol. LXIV, $n^{\circ} 143$ (20 juin 1973), p. 8.

, Arts et spectacles. Marie-Claire Blais consacrée par le magazine le Point . le Droit, vol. LXI, n 72 (20 juin 1973), p. 36.

ARTHUR, Sheila, *French Book World», The Gazette, vol. CXCIV (March 4. 1972). p. 48.

BELLEFEUILLE, André, aLittérature québécoise. Les Loups (sic)», les Cahiers de Cap-Rouge, vol. I, n० 1 (décembre 1972), pp. 73-76.

CLOUTIER, Pierre, Books in French Canada 72*, Books in Canada, vol. II, n० 1 (January-February 1973), p. 13.

COSSETTE, Gilles, :Le Laup de Marie-Claire Blais", Livres et Auteurs québécois. 1972, pp. 68-69.

DAVIES, Gillian, The Wolt and St. Lawrence Blues", The Fiddlehead, n० 104 (Winter 1975), pp. 128-133.

FRENCES, Davis, *The Wolf., The Dalhousie Review, no 54 (1974-1975), pp. 786-787.

J(ARDIN), Cliaudine), «Roman. Les loups entre eux», le Figaro littéraire, $n^{\circ} 1409$ (19 mai 1973), p. 14 (II).

LAMBERT, Jean-Pierre, a Le Loup", Rive gauche, mai 1972 (non vid).

LANE, William, A Confessionnal Novels, The Citizen, September 21, 1974 (non vidi).

LAVOIE, Charles, apour la défense et l'illustration de la tératologie (Mémoire et imagination dans le Loup de Marie-Claire Blais). Essai», Écrits du Canada francais, vol. XXXVII (1973), pp. 153-210.

LEECH. Maggie, «Waiting - but for what or who?», Sunday Books, October 5. 1974 (non vid).

LYON, George W., aNovel explores Nature of Love», The Albertan, February 22. 1975 (non vidh).

MARTEL, Réginald, \& Tout amour est l'amour $\%$ la Presse, vol. LXXXVIII, $n^{\circ} 21$ (4 mars 1972), p. D-3.

McKENNA, Isobel, "The Wolfn, the Bookshelf, September 21, 1975 (non vidi).

MONTALBETTI, Jean, "Le Loup, les horreurs de l'amour", le Point, 4 juin 1973 (non vidh). 
RICHMOND, John, «It's a Man's World», The Montreal Star, February 16, 1972 (non vids).

- _. Novel of Purity incarnate Stabs at both Heart, Mind s, The Montreal Star, vol. CIV, n 40 (February 17, 1972), p. 57.

SAINT-ONGE, Paule, "Chätelaine a lu pour vous", Châtelaine, vol. XIII, n' 6 (juin 1972), p. 14.

SAUNDERS. Tom. "Le Loup. Dark Genious», Winnipeg Free Press, August 24. 1974 (non vid).

SCULLY, Robert-Guy, "Le Loup de Marie-Claire Blais, publié mercredi. Un romanclasseurn, le Devoir, vol. LXIII, n 42 (19 février 1972), p. 15.

TREMBLAY, Robert, «Presqu'Amérique vous propose de lire le Loup ", Presqu'Amérique, vol. $1, n^{\circ} 7$ (mai-juin 1972), p. 36.

\section{Un Joualonais, sa Joualonie (A coour joual)}

(Anonyme), a Les livres en bref. Un Joualonais, sa Joualonie», le Québec en bref, vol. VII, $n^{\circ} 8$ (août 1973), p. 2.

BEAULIEU. Ivanhoé, « La vie est une 'vicieuse de chiennerie' *, le Devoir, vol. LXIV. $n^{\circ} 128$ (2 juin 1973), p. 15.

BEAUSOLEIL, Claude, aLire aujourd'hui», Hobo-Quebec, nº 8 (septembre 1973). p. 16.

BRUNEAU, Roger, a Le livre de la semaine. Un Joualonais, sa Jovalonie ", IAction Québec, vol. LXVI, n' 533 (2 juin 1973), p. 4.

DAVIES, Gillian, «The Wolf and St. Lawrence Blues", The Fiddlehead, $n^{\circ} 104$ (Winter 1975), pp. 128-133.

GODARD, Barbara, «La grande querelle, Un Joualonais, sa Joualonie», Journal of Canadian Fiction, vol. III, $n^{\circ} 3$ (1974), pp. 106-108.

MARTEL, Réginald, « Nous sommes tous des trous-de-culn, la Presse, vol. LXXXIX, $n^{\circ} 119$ (19 mai 1973), p. D-3.

MONTALBETTI, Jean, «Les héros du joual», le Magazine litteraire, n 86 imars 1974). pp. 28-29.

PIAZZA, François, «Une erreur *, Montréal-matin, vol. XLIII, $n^{\circ} 333$ (3 juin 1973), p. 17.

POISSON, Roch, «Un Joualonais, sa Joualonies, Nous. vol. I, n 2 (juillet 1973). p. 45.

RIVARD, Yvon, \& Marie-Claire Blais. Un Joualonais, sa Joualonie. Editions du Jour", Livres et Auteurs québécois, 1973, pp. 35-36.

TREMBLAY, Robert, «Comment ruer dans les brancards littéraires», le Soleil, vol. LXXVII, n० 131 (9 juin 1973), p. 42.

WERDEN, Gary, «Realism, Picaresque, Pseudo Confession „, Canadian Literature, n० 67 (Winter 1976), pp. 109-112.

Une liaison parisienne

(Anonyme), «Une liaison parisienne. Marie-Claire Blais, Editions Stanké-Québec», le Dimanche, vol. XLVI, n 151 (7 décembre 1975), p. 10.

- . Blais, Bessette, Leblanc: tragédie, ironie et humour $\nsim$, Montréal ce mois-ci, 27 février 1980, (non vidi).

- "Une liaison parisienne», le Livre canadien, vol. VII, n 90 (mars 1976).

AMPRIMOZ, Alexandre L., «Four Writers and Today's Quebec», The Tamarack Review, $n^{\circ} 70$ (Winter 1977), pp. 72-80.

ARGUIN. Maurice, «Nouveautés. Romans. Une liaison parisienne», Québec français, $n^{\circ} 21$ (mars 1976), pp. 8.9. 
BAACLAY, Pat, "An Expose of Parisian Society". Peterborough Examiner. November 24, 1979 (non vidi).

BASILE, Jean, "Une liaison a la Marıe-Claire Blais", le Devoir, vol. LXVIII, $n^{\circ} 26$ (31 Janvier 1976), p. 16.

BEAUSOLEIL. Claude, "Lire aujourd'hui», Hobo-Québec, nos 29-30 (mai-aoùt 1976). p. 3.

BURNINGHAM. Bradd, "Not much discovered on Voyage of Discovery", The Windsor Star, January 26, 1980 (non vidi).

DU BERGER HOWSE, Johanne, "Marie-Claire Blais. Une liaison parisienne ", Livres et Auteurs québécois. 1975, pp. 37-38.

DUFAUX, Paule-France, "La Liaison parisienne que décrit Marie-Claire Blais», le Soleil, vol. LXXIX, n० 283 (29 novembre 1975), p. C-4.

- "Marie-Claire Blais: le chemin qui va de la naiveté à la lucidité ", le Saleil, vol. LXXIX, n०283 (29 novembre 1975), p. C.5.

FAUSTMANN, John, «A Pallid, snivelling Lot who may leave you colds, the Vancouver Sun. November 3, 1979 (non vidi).

FRENCH, William, "In a Sense, A Literary Affair is about relations between Quebec and France. But Marie-Claire Blais promises much and delivers little and is disappointing”, The Globe and Mail (Entertainments), vol. CXXXVI, n० 40514 (Ocrober 13, 1979), p. 12.

GODBOUT, Jacques, *Ces voyages qui forment la jeunesse „, le Maclean. vol. XVI. $n^{\circ} 4$ lavril 1976), p. 12.

HALLADAY, Barbary, "A Literary Affair *, The Whig Standard Magazine. December 15. 1979 (non vidi).

HESSE. M.G., "A Literary Affair", The Ottawa Review, March 6, 1980 (non vidi).

JAN, Yrène, ane liaison parisienne de Marie-Claire Blais. La déception d'un Québécois», l'Aurore. décembre 1975 (non vidi).

JASMIN, Claude, «Livres. Poupart, le maharishi, Blais et Fleurette...., Actualité, vol. XVI, $n^{\circ} 4$ (avril 1976), p. 6.

LAURIER, Marie, «En déjeûnant avec Marie-Claire Blais. Tout écrivain a besoin de conseillers littéraires", le Devoir, vol. LXVIII, $n^{\circ} 289$ (11 décembre 1976). p. 32.

MARTEL, Réginald, "Le silence vaudrait mieux que le vide", la Presse, vol, XCl, n०291 (6 décembre 1975), p. D-4.

MCNICOLL, André, "Quebec vs France. Brilliant Novel bares Psyches", The Ottawa Citizen. November 3, 1979 (non vidi).

NODELMAN, Perry, a Satire turns to ugly Fantasy», The Ottawa Review, March 1980 (non vidi).

PETROWSKI, Nathalie. "Liaison parisienne pour Marie-Claire Blais», le Journal de Montréal, vol. XII n 176 (7 décembre 1975), p. 21. $n^{\circ} 159$ (9 décembre 1975), p. 42.

PIAZZA, François, a Un instant dans la vie de Marie-Claire Blais», Montréal-matin. vol. XLVI, $n^{\circ} 159$ (9 décembre 1975).

POULIN. Gabrielle, «Le roman. Une saison dans la vie des Français ou Une liaison parisienne de Marie-Claire Blais», Lettres québécoises. no 2 (mai 1976). pp. 3-5 (reproduit dans Romans du pays 1968-1979. Montréal. les Editions Bellarmin, 1980, pp. 314-320).

*Entre les lignes. Une liaison parisienne. Le prix Belgique-Canada 1976 a Marie-Claire Blais s, le Droit, vol. LXIV. $n^{\circ} 65$ (12 juin 1976), p. 14.

-. "Letters in Canada (...) Romans, récits, nouvelles, contes $n$, University of Toronto Quarterly, vol. XLV, n 4 (Summer 1976). p. 328. 
RICARD. François. aLittérature québécoise. Nos romancières*. Liberté. \# 105, vol. XVIII, $n^{\circ} 3$ (mai-juin 1976), pp. 95-98.

RUSSELL, George, "Nightmare's Child. Marie-Claire Blais has brought her chilling Universe back to Quebec», Weekend Magazine, October 23, 1976, p. 11 sqq.

TATE, Carolyn, "Culture Shock Abroad*, The Hamilton Spectator, January 5, 1980 (non vidi).

TREMBLAY, Robert, a Avec Marie-Claire Blais. En passant du coq à l'âne, de l'écriture au silence. Quand elle tente de pasticher Marcel Proust x, le Jour, vol. II, $n^{\circ} 231$ (5 décembre 1975), pp. 24-25.

VANASSE, André, aMarı-Claire Blais: Une liaison parisienne», Voix et Images, vol. I, n०3 (printemps 1976), pp. $456-457$.

WYAT, Louise, «Neophyte's Integrity battered by strange French Affair». The London Free Press. November 24, 1979 (non vidi).

These

PURVIS, Anne, aÉducation et initiation dans Une liaison parisienne de Marie-Claire Blais», mémoire de maitrise ès arts, Winnipeg, University of Manitoba, 1980.

\section{Les Nuits de l'Underground}

ADASKI, Ken, «Blais' private life exposed", The Toronto Star, May 19, 1979 (non vidi).

ARGUIN, Maurice, «Les Nuits de I"Underground», Québec trancais, n 31 loctobre 1978), p. 6.

BROCHU, André, « Marie-Claire Blais. Les Nuits de l'Underground „, Livres et Auteurs québécois, 1978, pp. 30-33.

BROWN, Alan, «Toujours gaie, toujours ennuyeuse», Books in Canada, vol. VIII, $n^{\circ} 7$ (August-September 1979), p. 16.

CIMON, Renée, «Les Nuits de I'Underground 1978).

CHRISTIAN, Jean, «De la solidarité *, Dernières nouvelles d'Alsace, 10 septembre 1978 (non vidi).

COHEN, Lori, «Blais' Novel is filled with Hope», The Examiner, July 5, 1979 (non vidi).

DI MARTOLEMEO. Nicole, aLes Nuits de l'Underground», le Courrier de Laval, 5 avril 1978 (non vidi).

EGERTON, Diane, * This kind of love story won't appeal to everyone $*$, London Free Press. September 8. 1979 (non vidi).

ETHIER-BLAIS, Jean, - Les carnets de Jean Ethier-Blais*, le Devoir, vol. LXX, $n^{\circ} 4$ (6 janvier 1979). p. 14.

FISCHMAN, Sheila, \& Blais gets Union Card», The Montreal Star, vol. CX, $n^{\circ} 32$ (February 9, 1978), p. 8-6.

FITZPATRICK, Marjorie A., "Marie-Claire Blais, les Nuits de I"Underground», The French Review, vol. LII, n 6 (May 1979), pp. 948-949.

FOURCASSIE, Sylvain, a Le semainier», les Nouvelles littéraires, vol. LVI, n² 636 (25 mai 1978), p. 23.

FREEDMAN, Adèle, "Marie-Claire's women burn their way through the pages", The Globe and Mail, vol. CXXXVI, n० 40384 (May 15, 1979), p. 17.

GAREBIAN, Keith, "Exploring the Underbelly of the Soul", The Montreal Star, vol. CXI, n० 91 (May 26, 1979). p. E-3.

GAUVIN, Lise, a Letters in Canada (...) Romans, récits et contes $\%$ University of Toronto Quarterly. vol. XLVIII, $n^{\circ} 4$ (Summer 1979). pp. 330-339 (voir pages 337-338).

GAY, Paul, antre les lignes. Les Nuits de I'Underground de Marie-Claire Blais. L'interprétation idyllique du saphismen, le Droit, vol. LXVI, n 18 (15 avril 1978), p. 23). 
GEMME, Gilles, "Les Nuits de I"Underground", le Canada trancais, 5 avril 1978 (non vidi).

HALEY, Louise, "Les Nuits de I'Underground sera porté à l'écran", le Journal de Montréal, May 1978 (non vidi).

HILL, Heather, "A Celebration of Love between Women", The Albertan, June 24 , 1979 (non vidi).

HOFNESS, John, "The Role of Sexual Orientation in Art", The Calgary Albertan. May 13, 1979 (non vidi).

LEGER, Jack-Alan, "Les Nuits de l'Underground", Nice-matin, 14 mai 1978. (non vidi)

LERTH, Linda, «Rights of Memory», Canadian Forum, vol. LIX, n 692 (September 1979), pp. 28-29.

MARCOTTE, Gilles, «Une saison dans la vie de Geneviève Aurès», le Devoir, vol. LXIX, n० 70 (25 mars 1978), p. 35.

McNiCOLL. André, «Novelist of Despair finds Defiant Hope», The Citizen, June 2. 1979 (non vidi).

MORLEY. Patricia, a Thesis Novel fails to meet Challengen, The Ottawa Journal. March 29, 1980 (non vidi).

MORGAN, Jean-Louis, «L'homme qui lit ". I"Intormation médicale et paramédicale. 2 mai 1978 (non vidi).

O'CONNOR, John, aLetters in Canada (...) Translations $\infty$, University of Toronto Quarterly, vol. XLIX, n 4 (Summer 1980), pp. 383-399 (voir pages 387-388).

POWERS, Gordon, «The Underground struggles of Humanity in a Desinterested World ». The Ottawa Journal, June 23, 1979 (non vidi).

ROY, Monique, «Marie-Claire Blais: 'Chaque livre est un engagement " $x$, le Devoir. vol. LXIX, n० 53 (4 mars 1978), p. 33.

SLONE, Ted, *Women in Love», Winnipeg Free Press. August 18, 1979 (non vidi).

SUTHERLAND, Ronald, "Nights in the Underground", The Globe and Mail, vol. CXXXVI, no 40436 (July 14, 1979), p. 41.

WACHTEL, Eleanor, aNights of the Underground", The Vancouver Sun, July 13 , 1979 (non vidi).

WESLEY, David, a Underground fades into the Thin Air", The Hamilton Spectator. July 16, 1979 (non vidi).

WINTERS, Robert, "Morbidity of Writing Deceptive", The Montreal Gazette, vol. CCl (March 2, 1979), p. 35.

\section{Le Sourd dans la ville}

(Anonyme), aUn deuxième prix du Gouverneur général à Marie-Claire Blais», la Presse, vol. XCVI, n 96 (22 avril 1980), p. A-18.

- « Governor General's Prizes go to Three Montreal Writers», The Montreal Gazette, vol. CCII (April 19, 1980), p. 109.

- aCompassion relieves Dark Side of Human Scenes; The Prairie Messenger. September 13, 1981 (non vidi).

ADASKI, Ken, «Blais' bold prose experiment: one paragraph of 220 pages», The Toronto Star, June, 20, 1980 (non vidi).

ALLISTON, Karen, "Blais' dense pastiche of inner monologues». The Varsity, October 9, 1981 (non vidi).

BARCLAY, Pat, « Canada's ten best books of the year , The Victoria Times. December 24. 1981 (non vidi).

BAROCHE, Christiane, "Le Sourd dans la ville par Marie-Claire Blais», le Sud (Marseille), vol. XI, nos 37-38 (mai 1981), pp. 196+197.

BEAULIEU. Michel, "Le chef-d'œuvre de Marie-Claire Blais», le Livre d'ici, 27 février 1980. 
BROWN, Alan, "Blais listens to her Travellers with Compassion». The Montreal Gazette. vol. CCII (March 15. 1980), p. 96.

CAMERON, Elspeth, "Connoisseur of Calamity», Saturday Night, vol. XCVI, $n^{\circ} 8$ (September 1981), pp. 68, 70.

CASANOVA, Nicole, "Le Sourd dans lo ville», le Quotidien de Paris, 1er juillet 1980 (non vidi).

CHARTET, Jean-Claude, *Les bonnes pages du mois*, Ilonne républicaine, juillet 1980 (non vidi).

CRAWLEY, Ennis, a Life as Series of Pictures*, The Why Standard Magazine, Juty 1981 (non vidi).

CZARNECKI, Mark, * Bloody Clouds of Works*, Maclean's, vol. XCIII, n० 12 (March 24, 1980), pp. 56-57.

DESCAZEAUX, P.. "Le Sourd dans la ville*, les Livres (Paris), juin 1981 (non vidi).

DORION, Gilles, «Le Sourd dans la ville ", Québec français, n 38 imai 1980), p. 10.

DURAND, Dominique, "Le Sourd dans la ville», le Canard enchaine, 9 juillet 1980 (non vidi).

ÉTHIER-BLAIS, Jean, aLes carnets de Jean Ethier-Blais», le Devoir, vol. LXXI, n० 34 (9 février 1980), p. 28.

FISCHMAN, Sheila and MCCORMICH, Marion, aFour Montrealers win Governor General's Awards», The Montreal Gazette, vol. CCll (April 21, 1980). p. 28.

FISCHMAN, Sheila, aThe Underside of the City., The Montrea/ Calendar Magazine. June 1981 (non vidi).

FRENCH, William, \&Blais Novel is tough going, but well worth the journey», The Globe and Mail, vol. CXXXVIII, n० 41031 (June 11, 1981), p. 19.

GAUER, Stephen, aMontreal Writers deliver Different Views», Now. September 1981 (non vidi).

GARCIN, Jérôme, * Le guide des nouvelles littéraires*, les Nouvelles littáraires, vol. LVIII, $n^{\circ} 2743$ (26 juin 1980), p. 6.

LABONTE, Richard, "Sensitive Work depicts Story of City Lost Souls *, The Ottawa Citizen, July 18, 1981 (non vidi).

MARTEL, Réginald, «Écrire simplement la douleur de vivre», la Presse, vol. XCVI, n०34 (9 février 1980), p. C-3.

McGRATH, Joan, «Deaf to the City ., Canadian Materials, March 1982 (non vidi).

MÉLANCON. Robert, aLa vision tragique de Marie-Claire Blais», le Devoir, vol. LXXI, n० 21 (26 janvier 1980), p. 19.

OUELLETTE-MICHALSKA, Madeleine, «Livres. Voyageries intérieures » Châtelaine, vol. XXII, n 4 (avril 1981), p. 32.

PARE, Yvon, "Le roman de l'espoir sans espoir», le Quotidien du Saguenay-Lac Saint-Jean (cahier aArts. Télé. Loisirs m), vol. VII, $n^{\circ} 110$ (9 février 1980), p. 7.

POULIN, Gabrielle, « Le roman II. Un torrent qui se fige. Le Sourd dans la ville de Marie-Claire Blais». Lettres québécoises, n 18 (été 1980), pp. 19-21.

ROSS. James, a Gloom and Doom bleed from New Blais Novelø, The Spectator. August 8, 1981 (non vidi).

ROYER, Jean, «Marie-Claire Blais. Ecrire contre la mort *, le Devoir, vol. LXXI, $n^{\circ} 16$ (19 janvier 1980), p. 17.

STRATFORD. Philip, «Marie-Claire Blais prowling the periphery of solitude*, Quill and Quire, June 1981 (non vidi).

STEWE, Paul, «xploring a Labyrinth of Tongues; from the Folklore of Quebec to a Trenchant Analysis of the Soviet Society $x$, Books in Canada, vol. $X, n^{\circ} 8$ (October 1981), p. 28.

VIATTE, Auguste, «Marie-Claire Blais»: le Sourd dans la villew, Conjonction. septembre 1980 (non vidi). 
VILLIERS. Mark de, "Deat to the City", Canadian Churchman, October 1981 (non vidi).

WALSH, Barbara, "Angels and Madonnas of the Gutter», The Review. September 22. 1981 (non vidi).

WILSON, Jean, "Deaf to the City is Hi-Fidelity", Broadside, February 4. 1982. (non vidi).

\section{Visions d'Anna}

AUDET, Noèl, "Une écriture vertigineuse », le Devoir, vol. LXXIII, n 106 (8 mai 1982), p. 19.

BEAULIEU, Michel, «Marie-Claire Blais, la face cachée de la lune», le Livre d'ici, 7 juillet 1982 (non vidi).

CHAMBERLAND, Roger, «Visions d゙Anna, Marie-Claire Blais», Québec français. n० 47 loctobre 1982), pp. 6-7.

LÉVESQUE, Gaëtan, "Regards lucides sur la société», Voix et Images, vol. VIII. n' 1 (automne 1982), pp. 154-158.

MAILHOT, Michèle, "Le roman I. Visions d'Anna de Marie-Claire Blais (Éditions Stanké)». Lettres québécoises. $n^{\circ} 27$ (automne 1982), pp. 18-19.

MARCOTTE, Gilles, “Pantagruel et Anna : meurtres et cauchemar éveillé n, Actualité. vol. VII, n० 8 (aoùt 1982). p. 67.

MARTEL, Réginald, «Marie-Claire Blais. L'apocalypse selon Anna», la Presse. vol. XCVIII, $n^{\circ} 101$ (1er mai 1982), p. C-3.

THÉORETT. France, «Roman québécois. Mères et filles en procès», Spirales, $n^{\circ} 27$ (septembre 1982), p. 7.

TREMBLAY, Régis, "Marie-Claire Blais. Bien écrire... et bien souffrir», le Soleil, vol. LXXXVI, n० 111 (8 mai 1982), p. D-1.

___ « Le nouveau Marie-Claire Blais. Une immense tirade sur l'apocalypsen, le Soleil, vol. LXXXVI, no 111 (8 mai 1982), p. D-8.

\section{THÉATRE}

\section{L'Exócution}

(Anonyme), *Begons, subtitles: It's bilingual TV drama*. The Globe and Mail, vol, CXXIII, n' 36571 (February 25, 1967). p. 10.

—_ - Une pièce de Marie-Claire Blais créée au Rideau Vert en 1968 „, la Presse, vol. LXXXIII, $n^{\circ} 218$ (20 septembre 1967). p. 76.

-, De Marie-Claire Blais à Pinter $*$, le Devoir, vol. LVIII. $n^{\circ} 217(20$ septembre 1967). p. 11.

—_. «L'Exécution», Joliette-journal, vol. XV, nº 15 (18 septembre 1968), p. 6. . "Programmation exceptionnelle au Theâtre du Rideau Vert", le Droit. vol. LV, n० 158 (30 septembre 1967), p. 12.

- . Marie-Claire Blais nous parle de sa pièce I'Exécution». la Presse. vol. LXXXIV, $n^{\circ} 57$ (12 mars 1968), p. 12.

- "L'Exécution au Rideau Vert*, le Messager de Lachine, vol. XXXVIII, $n^{\circ} 11$ (14 mars 1968), p. 17.

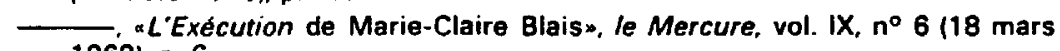
1968), p. 6.

- "Marie-Claire Blais est jouée au Rideau Vert», le Droit, vol. LV, n॰ 303 (21 mars 1968), p. 13.

$n^{\circ} 18$ (23 mars 1968), p. 9 . 
¿Au Stella, les 'kétaines' ne comprennent pas Marie-Claıre Blais», le Grand Journal illustré, vol. II, no 14 (1er avril 1968), p. 26.

- "Création canadienne de Marie-Claire Blais au Aideau Vert", "Action, vol. LXI, n० 18236 (4 avril 1968). p. 5.

vol. LVI, $n^{\circ} 10$ (6 avril 1968), p. 13.

. Marie-Claire Blais peint un aspect de la violence dans r'Exécution». le Droit, vol. LVI, n० 14 (11 avril 1968). p. 29.

- auteur de la pièce du même nom, Marie-Claire Blais lance l'Exécution ". Telé-radiomonde, vol. XXIX, $n^{\circ} 21$ (13 avril 1968), p. 4. p. 17.

, "Le coin des livres», la Terre de chez-nous, vol. XL, nº (17 avril 1968), 19. "Des jeunes jouent dans l'Exécution», le Droit, vol. LVI, n 20119 avril 1968), p. 13.

_.' Nouvelles brèves», le Petit Journal, vol. XLII, n 36 (30 juin 1968), p. 25.

BAlLEY, Bruce, "The Execution», Quill and Quire, vol. XLIII, n० 3 (February 15 , 1977), p. 8.

BASILE, Jean, „Faut-il exécuter Marie-Claire Blais?", le Devoir, vol. LIX, n॰ 82 (6 avril 1968), p. 13.

BERNIER. Thérèse, a L'Exécution créée le 15 mars. Marie-Claire Blais se tourne maintenant vers le théâtre». le Droit, vol. LV, $n^{\circ} 293$ (9 mars 1968), p. 18 (reproduit dans le Nouvelliste, vol. XLVIII, n० 111 (11 mars 1968), p. 8; dans le Soleil, vol. LXXI, $n^{\circ} 63$ (12 mars 1968). p. 31 et dans la Tribune, vol. LIX, $n^{\circ} 15$ (12 mars 1968), p. 12).

BRINDAMOUR, Yvette, «Bienvenue Marie-Claire Blais I», Programme de l'Exécution. Montréal. Rideau Vert, mars 1968.

COGNARD. Alain, aL'Exécution», le Mercure, vol. IX, n० 7 (30 mars 1968), p. 6. COTE, Roland, alci et là...., Dernière Heure, vol. II, n 48 (27 août 1967), p. 17.

D'AUTEUIL, Georges-Henri, aLe Théátre. L'Exécution», Relations, n० 327 (mai 1968), pp. 158-159.

DEMERS, Edgar, a L'Exécution de Marie-Claire Blais jouée au Capitol», le Droit, vol. LVI, n'23 (23 avril 1968), p. 14.

GARON, Jean, "Une violence qui sommeille», le Soleil, vol. $L X X I, n^{\circ} 94$ (18 avril 1968). p. 38.

G(ERMAIN), J(ean)-C(laude), «Marie-Claire Blais: 'Un groupe d'adolescents, c'est tellement plus vrai; on peut tout leur faire dire' ', le Petit Journal, vol. XLII, $n^{\circ} 20$ (10 mars 1968), p. 49.

- «Au théâtre. L'Exécution: dix minutes de théâtre», le Petit Journal, vol. XLII, $n^{\circ} 22$ (24 mars 1968), p. 55.

GIROUARD, Michel, «arie-Claire Blais et la sensationnelle rentrée de Daniel Gadouas au Stella», Télé-radiomonde, vol. XL, n० 20 (7 avril 1968). p. 19.

GREFFARD, Madeleine, “Le théâtre*. Études littéraires, vol. II, n² 2 (août 1969), pp. 221-237.

HELLER, Zelda, «Rideau Vert presents I'Exécution by Marie-Claire Blais, a Dark New Play, The Montreal Gazette, vol. CXC (March 18, 1968), p. 28.

HENORY, Tom, «The Execution*, Books in Canada, vol. VI, n० 4 (April 1977), p. 19.

HILL. Harriet, afacts \& Fancies», The Montreal Gazette, vol. CLXXXIX, n० 2 (May 30, 1968), p. 17.

IRWIN, Joan, "L'Exécution: Study in Horror*, The Montreal Star, vol. CVIII, n 66 (March 18, 1968), p. 27.

KARCH. Marie O'Nell et Pierre-Paul, a Le destin tragique de l'homme dans IExécution de Marie-Claire Blais», Archives des lettres canadiennes, tome V. le Théâtre canadien-français, Montréal, Fides, 1976, pp. 637-645. 
KEMPF, Yerrı, «Le Québec: un théâtre libre mais...n, Tréteau, $n^{\circ} 6$ inovembre 1967l. pp. 16-19.

LÉVY. Bernard, "Théâtre. Des phrases longues et belles. L'Exécution», Sept-jours, vol. II, $n^{\circ} 28$ (24-30 mars 1968), p. 48.

MAILHOT, Laurent, "L'Exécution de Marie-Claire Blais". Livres et Auteurs canadiens, 1968 , pp. 72-73.

MAITTRE, Manuel, "Théâtre 67-68: quarante pièces, quinze créations canadiennes», la Patrie, vol. LXXXVIII, n 42 (22 octobre 1967), pp. 32-33.

MAJOR, André, "L'Exécution de Marie-Claire Blais: un drame de la responsabilité au Rideau Vert le 15 mars prochain», le Devoir, vol. LIX, n 58 (9 mars 1968), p. 11.

—_. «L'Exécution ou la cruauté absurden, le Devoir, vol. LIX. n 66 (19 mars 1968), p. 12.

MAJOR, Henriette, "Tout sur tout ", Châtelaine, vol. IX, n 3 (mars 1968), p. 10.

MORISSETTE, Louis, *Marie-Claire Blais, auteur dramatiquen, le Journal de Montréal, vol. IV, no 229 (19 mars 1968), p. 8.

NADEAU, Monic, "Le phénomène Marie-Claire Blais», Tele-radiomonde, vol. XXVIII, $n^{\circ} 9$ (21 janvier 1967), p. 14.

PIAZZA, François, *Votre critique au théâtre. L'Exécution", Échos-vedettes, vol. VI, $n^{\circ} 11$ (30 mars 1968), p. 19.

-Une saison de théâtre qui démarre sur la pointe des pieds". Échosvedettes, vol. V. $n^{\circ} 38$ (16 octobre 1967), p. 7.

_. ane saison (de théâtre) dans la vie de Marie-Claire Blais \%, Échosvedettes, vol. VI, $n^{\circ} 9$ (16 mars 1968), p. 6.

PONTAUT, Alain, Dictionnaire critique du théstre québécois, Montréal, Éditions Leméac, 1972, pp. 21-23.

PRESSE CANADIENNE, «Bicultural Play», Quebec Chronicle-Telegraph, vol. CCIII, $n^{\circ} 207$ (February 22, 1968), p. 14.

RINFRET, Edouard-G., le Théâtre canadien d'expression française, Montréal, Éditions Leméac, vol. 1, 1975, pp. 72-73.

ROBIDOUX, Rejean, ${ }^{2}$ Exécutionn, University of Toronto Quarterly, vol. LVIII. $n^{\circ} 4$ (July 1969), p. 478.

ROYER, Jean, « $L$ 'Exécution ou la saison continuelle de Marie-Claire Blais $*$ I'Action. vol. LXI, n० 18237 (5 avril 1968), p. 19.

- "L'Exécution ou la tragédie de l'enfance assassinée. l'Action, vol. LXI. $n^{\circ} 18247$ (18 avril 1968), p. 5.

SABBATH, Lawrence, * Rideau Vert prepares for 19th Season $*$, The Montreal Star, vol. XCIX, $n^{\circ} 223$ (September 23, 1967), p: 30.

\section{Deux destins}

HOULE, René, «Deux destins", lci Radio-Canada, nº 52 (5 mai 1973), pp. 19-20.

\section{La Roulotte aux poupées}

(Anonyme), «Une pièce de Marie-Claire Blais», la Presse, vol. LXXVI, $n^{\circ} 292$ (28 septembre 1960), p. 32.

. Nouvelles inédites», Ici Radio-Canada, vol. I, n० 38 (16-22 décembre 1967), p. 16.

- Les talents de Marie-Claire Blais et de Geneviève Bujold réunis dans la Roulotte aux poupées», le Journal de Montréal, vol. Ill, n 214 (1er mars 1967). p. 19.

- "Geneviève Bujold dans une pièce de Marie-Claire Blais à la TV . la Tribune, vol. LVIII, no 14 (11'mars 1967), p. 16. 
- "La Roulotte aux poupées", Ici Radio-Canada, vol. I, n 50 (11-17 mars 1967). p. 1.

- "La Roulotte aux poupées», Madame, vol. I, n 12 (7 mars-7 avril 1967), p. 2.

CÔTE, Fernand, "Geneviève Bujold dans une pièce de Marie-Claire Blais», Divertissement, vol. I, $n^{\circ} 12$ (mars 1967), p. 8.

HÉNAULT, Gilles, "La Roulotte aux poupées. OEuvre de Marie-Claire Blais à I'Atelier du Proscenium», le Devoir, vol. LI, n 228 (6 octobre 1960), p. 12.

MAJOR, André, a Radio-télévision. La Roulotte aux poupées», le Devoir, vol. LVIII. $n^{\circ} 61$ (14 mars 1967), p. 8.

PERRAULT, Luc, *Un drame de Marie-Claire Blais que tous les Canadiens verront *, la Presse (supp.), vol. LXXXIII, n 48 (25 février 1967), p. A-1.

\section{Eleonor}

(Anonyme), a Les comédiens de l'Estoc présentent: Eleonor de Marie-Claire Blais *, le Carabin, vol. $X X, n^{\circ} 8$ (17 novembre 1960), p. 5.

GARANT, Patrice, «L'Estoc continue d'impressionner... Eléonor», le Carabin. vol. XX, n०9 (24 novembre 1960). p. 5.

LAROCHE, Ghislain, aL'Estoc a joué... Eléonorm, le Carabin, vol. XX, n० 9 (24 novembre 1960), p. 5.

\section{Fidvre et Autres Textes dramatiques}

(Anonyme), \& Fièvre et Autres Textes dramatiques „, le Livre canadien, vol. V, n 267 (octobre 1974).

BEAUDOIN, Réjean, "En toutes lettres. Fièure de Marie-Claire Blais. Une conscience qui tue le personnagex, le Jour (supp.), vol. I. n' 107 (6 juillet 1974), p. V-2.

GAY, Paul, «Parlez-moi... de livres. Un vent de destruction. Fière*, le Droit, vol. LXII, n 161 (5 octobre 1974), p. 19.

KARCH, Mariel et Pierre-Paul, «Marie-Claire Blais. Fidvre et Autres Textes dramatiques. Éditions du Jour», Livres et Auteurs québécois, 1974. pp. 178-179.

PIAZZA, Francois, aMarie-Claire Blais: la fièvre au cour», Montreal-matin, vol. XLIV, $n^{\circ} 297$ (28 avril 1974), p. 18.

THERIAULT, Jacques, «Marie-Claire Blais nous revient avec un recueil de cinq pièces *, le Devoir, vol. LXV, $n^{\circ} 92$ (23 avril 1974). p. 12.

\section{Sommeil d'hiver}

(Anonyme), «Le théâtre de Marie-Claire Blais», le Soleil, vol. LXXVIII, n 201 (27 août 1974). p. 39.

\section{Un couple}

(Anonyme), a Un couple de Marie-Claire Blais «, le Jour, vol. I, n 236 (6 décembre 1974), p. 13.

\section{L'Océan (suivi de) Murmures}

ARGUIN, Maurice, «Nouveautés. Théâtre. L'Océan suivi de Murmures», Québec francais, $n^{\circ} 26$ (mai 1977). p. 10.

BASILE, Jean, «Une dramatique de Marie-Claire Blais $"$, le Devoir, vol. LXVIII, n 126 (31 mai 1976), p. 10.

- a Marie-Claire Blais entre Océan et Murmures. 'Il est évident que le Québec est extrèmement dur pour ses écrivains " $"$ le Devoir, vol. LXIX, n० 40 (19 février 1977), p. 17. 
BEAUDOIN, Réjean, "Le théâtre d'auteurs", le Jour, vol. I, nº 17 (27 mai 1977). p. 35.

BOURQUE, Paul-André, "Marie-Claire Blais. L'Océan suivi de Murmures. Éditions Quinzen. Livres et Auteurs québécols, 1977, pp. 189-191.

COTE. Fernand, “L'Océan de Marie-Claire Blais”, /ci Radio-Canada/Télévision. vol. $X, n^{\circ} 22$ (22-28 mai 1976), p. 10.

DOSTIE, Gaëtan, “Le livre québécois. Marie-Claire Blais, comédienne par défaut », le Jour, vol. I. n' 5 (4 mars 1977), pp. 34-35.

GERMAIN, Georges-Hébert, "L'Océan suivi de Murmuress, Nous, vol. IV, $n^{\circ} 11$ (avril 1977), p. 15.

LASNIER, Louis, «L'Océan suivi de Murmures", Nos livres, vol. Viil, n 164 (mai 1977).

PAGE. Pierre et LEGRIS, Renée, Répertoire des dramatiques québécoises à la télévision. 1952-1977. Montréal, Fides, 1977, 252 pages (voir page 49).

PIAZZA, François, * L'Océan suivi de Murmures $*$, Montréal-matin, vol. XLVII, $n^{\circ} 231$ (20 février 1977), p. 18.

SAINT-JACQUES, Denis, a Le thêâtre qu' on joue (sic) L'Océan suivi de Murmures *, Lettres quebécoises, no 6 (avril-mai 1977), pp. 19-21.

\section{Une femme et les Autres}

S(TÉPHANE), Jean), «Une femme et les Autres de Marie-Claire Blais*, Ici RadioCanada, n० 193 (17 janvier 1976), p. 3.

\section{La Nef des Sorcières}

CAMERLAIN, Lorraine, "La Nef des sorcières*, Jeu. Cahiers de thestre, n 14 (1980-1981), pp. 216-217.

\section{POESIE}

\section{Pays voilés et Existences}

(Anonyme), «La production littéraire en 1964», le Canada français, vol. CV, $n^{\circ} 33$ (7 janvier 1965), p. 20.

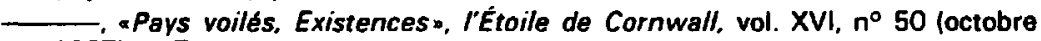
1967). p. 7.

CHAMPAGNe, Michel, aLa vie des livres. Place à la poésie», l'Action, vol. LVI, n' 16844 (17 aoùt 1963), p. 4.

D'ANJOU, Joseph, *Les livres. Marie-Claire Blais: Pays voilés», Relations, $n^{\circ} 271$ (juillet 1963), p. 216.

_. * Les livres. Marie-Claire Blais. Existences», Relations, n²97 (septembre 1965), p. 271.

GOULET, Elie, aLes livres canadiens. Littérature. Pays voilés. Podmes», Culture, vol. XXIV, n० 3 (septembre 1963), p. 302.

HALI DAY, Jean, «Notes bibliographiques", Revue de l'universite Laval, vol. XVIII, $n^{\circ} 7$ (mars 1964), p. 688.

HAMELIN, Jean, $\propto$ De nouveau le pays. J.-Guy Pilon et Marie-Claire Blais $*$, le Devoir, vol. LIV, no 128 (1er juin 1963). p. 10.

HOPKINS, Aline, «Pays voilés *, le Messager, vol. XV, n 18 (mai 1968), p. 12.

LAGACE, Lorraine, aMarie-Claire Blais, Existences. 'J'ai lourdement vécu aujourd'hui's, le Droit, vol. LII, n 203 (29 août 1964), p. 17.

LAPOINTE, Gatien, aHorizons littéraires. Existences, poèmes de Marie-Claire Blais», le Soleil, vol. LXVII, n² 233 (26 septembre 1964), p. 12. 
LAROCHE, Max(imilien). "Existences de Marie-Claıre Blaıs". Livres et Auteurs canadiens, 1964, pp. 65-67.

LEGARE, Romain, a Les livres canadiens. Littérature. Existences. Poèmes», Culture. vol. XXV, n० 4 (décembre 1964), p. 383.

LEVY, Bernard, “Livres. Un retour aux sources», Sept-jours, vol. II, $n^{\circ} 3(1-7$ octobre 1967). pp. 44-45.

MARCEL, Jean (pseudonyme de Jean-Marcel PAQUETTE), "Chroniques. Les écrits et les livres. Existences et souvenirs. Marie-Claire Blais, un poète de l'existence . I'Action nationale, vol. LIV. $n^{\circ} 3$ (novembre 1964), pp. 276-278.

MARCOTTE, Gilles, « Littérature. Reconnaissance de l'homme et du pays *, la Presse, vol. LXXXIX, n० 176 (11 mai 1963), p. 8.

MÉLANÇON, André, a Notices bibliographiques. Littérature canadienne. Littérature. Blais (Marie-Claire). Existences». Lectures, vol. XII, $n^{\circ} 1$ (septembre 1965), p. 11.

PARAOIS. Suzanne, al'envers des romans de Marie-Claire Blais», le Soleil, vol. LXXII, n० 274 (22 novembre 1967). p. 39.

PILON, Jean-Guy, «Réédition des poèmes de Marie-Claire Blais ", le Devoir, vol. LVIII, $n^{\circ} 220$ (23 septembre 1967), p. 15.

ROBERT, Guy, «Pays voilés de Marie-Claire Blais», Livres et Auteurs canadiens, 1963 , p. 65.

- " "Littérature et beaux-arts. Une cunre de Marie-Claire Blais. Les poèmes de Pays voilésw, le Petit Journal, vol. XXXVIII, n 18 (23 fóvrier 1964), p. A-48.

SYLVESTRE. Guy, * Les livres. Les lettres canadiennes-françaises. Existences de Marie-Claire Blais*, le Devoir, vol. LV, n० 192 (15 aoút 1964), p. 14 (reproduit dans Québec, vol. Il (février 1965), pp. 101-102).

- Livres en français. Poésien. University of Toronto Quarterly, vol. XXIII, n० 4 (July 1964), p. 503.

- "Livres en françaıs. La poésiex, University of Toronio Quarterly, vol. XXIV, $n^{\circ} 4$ (July 1965). pp. 464-465.

VALIQUETTE, Bernard, a la bonne pege. Marie-Claire Blais: Pays voiles. Existences*, Echos-vedettes, vol. VI, n० 9 (20 janvier 1968), p. 19.

-. "En bouquinant., Échos-vedettes, vol. VI, $n^{\circ} 14$ (20 avril 1968), p. 27.

\section{RECIT}

\section{Los Voyageurs sacrés}

(Anonyme), "Les livres. Les Voyageurs sacrés, récit de Marie-Claire Blais», SeptJours, vol. IV, n 6 (25 octobre 1969), p. 31.

- "Littérature. Avez-vous lu? Les Voyageurs sacrés", la Presse, vol. LXXXV, $n^{\circ} 284$ (6 décembre 1969), p. 31.

CLOUTIER, Cécile, «Les Voyageurs sacrés*, le Droit, vol. LVIII, n 201 (22 novembre 1969), p. 14.

DAVIES. Robertson, «Elegant Egoists. The Day is Dark and Three Travelers», New York Times Book Review, April 30. 1967, p. 4.

FERRON. Jacques, « Gabrielle Roy et Réjean Ducharme», le Petit Journal, vol. XLIV, $n^{\circ} 2$ (2 novembre 1969), p. 71.

- , Les arts et les autres. Les belles-lettres putassières», le Magazine Maclean, vol. X, n' 12 (décembre 1970), p. 50.

GAY, Paul, «Les Voyageurs sacrés (ou la tentation d'immortalité)», le Droit, val. LVII. n' 171 (18 octobre 1969), p. 7.

HAMELIN, Jean, «La vie littéraire par Jean Hamelin. Au tome XIV des Ecrits: le théâtre», le Devoir, vol. LIII, $n^{\circ} 270$ (17 novembre 1962), p. 11. 
LEPAGE. Yvan-G., aLes Voyageurs sacrés de Marie-Claire Blais*, Livres et Auteurs québécois, 1969, pp. 26-27.

MARCOTTE, Gilles, aLes livres. Littérature canadienne", la Presse (supp.), vol. LXXIX, n० 18 (3 novembre 1962), p. 8.

MARTEL, Réginald. * Littérature. Le retour de Pauline Archange. Les Voyageurs sacrés», la Presse, vol. LXXIX, no 18 (15 novembre 1969). p. 8.

PARADIS, Suzanne. L'envers des romans de Marie-Claire Blais*, le Soleil, vol. LXXII, n' 274 (22 novembie 1969), p. 39.

ROBERT, GuY, «Cinq poèmes féminins», Livres et Auteurs canadiens, 1962. pp. 44-46.

ROBIDOUX, Réjean, *Livres en français. Romans, récits, nouvelles, contes". University of Toronto Quarterly, vol. XXXIX, n० 4 (July 1970), p. 437.

ROCHON, Claire. -Les Voyageurs sacrés de Marie-Claire Blais: une dialectique existentielle de l'imaginaire», Co-incidences, vol. IV, nos 2-3 (mai-décembre 1980), pp. 109-117.

T(HÉBERGE). J(ean)-Y(ves), «Un récit de Marie-Claire Blais. Les Voyageurs sacrés», le Canada français, vol. $\mathrm{CX}, \mathrm{n}^{\circ} 22$ (22 octobre 1969), p. 36. 